\title{
INTEGRATING BWM AND ARAS UNDER HESITANT LINGUISTIC ENVIRONMENT FOR DIGITAL SUPPLY CHAIN FINANCE SUPPLIER SECTION
}

\author{
Huchang LIAO $\mathbb{1}^{*}$, Zhi WEN ${ }^{\circledR}$, Lili LIU* \\ Business School, Sichuan University, Chengdu 610064, China \\ Received 30 January 2019; accepted 24 May 2019
}

\begin{abstract}
In the era of intelligence and informatization, digital supply chain finance (DSCF) has become one of the important trends in the development of supply chain finance. With the gradual increase of DSCF suppliers and various requirements of small and medium-sized enterprises for suppliers in providing financing services, selecting the most suitable DSCF supplier is of great significance for most small and medium-sized enterprises to expand reproduction and improve competitiveness. To address such a decision-making problem, this paper proposes a new multi-expert multiple criteria decision-making model by integrating the Best Worst Method (BWM) and Additive Ratio ASsessment (ARAS) method under the hesitant fuzzy linguistic environment, in which the hesitant fuzzy linguistic BWM method is applied to determine the weights of criteria while the hesitant fuzzy linguistic ARAS method is proposed to rank the candidate suppliers. A case study is given to demonstrate the procedure of the proposed method for the selection of optimal DSCF suppliers, which shows the feasibility of the proposed method. Finally, sensitivity analysis and comparative analyses are provided to testify the applicability and superiority of the proposed method.
\end{abstract}

Keywords: digital supply chain finance, hesitant fuzzy linguistic terms set, best worst method, additive ratio assessment, supplier selection, multiple criteria decision making.

JEL Classification: C44, D70, D81, L83.

\section{Introduction}

Most small and medium-sized enterprises (SMEs) engaged in entity manufacturing often face the situation of low credit levels, few fixed assets collateral and scarce financing channels. It not only hinders the transformation and upgrading of these SMEs, but also limits the operational efficiency of the whole industrial chain. The supply chain finance (SCF) is a financing mode in which financial institutions connect core enterprises with upstream and downstream enterprises to provide flexible financial products and services to suppliers with

*Corresponding author. E-mail: liaohuchang@163.com

\#Corresponding author. E-mail: 11118906@qq.com 
capital demand (L. Zhang, Hu, \& D. Zhang, 2015). To some extent, the SCF is conducive to solving the long-standing problem of financing difficulty and high cost in SMEs. At present, most literature concerning decision-making problems of the SCF mainly focus on evaluating the credit risk of SMEs from the perspective of SCF suppliers (Zhang et al., 2015; Zhao, D. Wang, \& B. Wang, 2018). However, there are only few literature on how to choose suitable SCF suppliers from the perspective of SMEs, which reveals that SMEs can only passively choose SCF suppliers to finance most of the time. This leads to some limitations of SCF in solving financing problems for SMEs with low credit level.

DSCF is a financial business innovation with "double light" ("light assets" and "light capital") gene. Compared with the traditional SCF, the innovation of DSCF is mainly manifested in three aspects: more abundant financial ecology, more intelligent financial services, and more significant effect of enabling efficiency. The DSCF reduces the credit risks of SMEs through extensive information, multi-dimensional data and multi-credit support technology, and thus effectively solves the financing difficulties of SMEs. The digital supply chain (DSC) can be regarded as an advanced intelligent technology system with massive data processing capability and good collaboration and communication for digital information of whole supply chain (Büyüközkan \& Göcer, 2018). Therefore, the DSCF can be seen as the combination of DSC and SCF. It is a product of the digital development of SCF, and can lower the financing threshold and expand the scope of financing services. Thus, it increases the possibility for SMEs to select suitable suppliers for financing activities.

In this era of intelligence and informatization, the DSCF has become one of the important trends in the development of SCF. With the gradual increase of DSCF suppliers and the various requirements of SMEs for suppliers to provide financing services, selecting a suitable DSCF supplier is of great significance for most SMEs to expand reproduction and improve competitiveness. A key problem in supplier selection is to seek the best supplier among several alternatives according to various criteria, which can be regarded as a Multiple Criteria Decision Making (MCDM) problem (Badi \& Ballem, 2018). Therefore, the research question of this paper is how to use an appropriate method to solve the MCDM problem of selecting suitable DSCF suppliers for SMEs.

The hesitant fuzzy linguistic term set (HFLTS) (Rodríguez, Martinez, \& Herrera, 2012) is a successful means to reflect the fuzziness and hesitation of the evaluation information as it can be served to express several linguistic terms or comparative linguistic expressions in conjunction with context-free grammar. BWM can be used to derive criteria weights, which has higher consistency and computational efficiency, and ARAS can be employed to rank alternatives, which is characterized by high efficiency and can be easily extended to other environments to solve a great deal of practical problems. Hence, this paper dedicates to proposing a multi-expert MCDM method combining the HFL-BWM and HFL-ARAS methods. The HFL-BWM is applied to determine the weights of criteria with HFL assessments under the multi-expert MCDM environment, while the extension of the ARAS method, named the HFL-ARAS method, is used to rank the alternatives whose performances are represented by hesitant fuzzy linguistic elements (HFLEs) (Liao, Xu, Zeng, \& Merigó, 2015b). Combining the BWM and the ARAS method under the HFL environment enables DMs to deduce a reasonable and efficacious solution for cognitive complex decision-making problems under 
uncertain environment, taking advantage of the ability of expressing preferences with high consistency provided by the BWM and the ability of efficient ranking of the ARAS method.

The novelty of this paper lies in following points:

- The HFL-BWM is extended to the multi-expert MCDM environment, which further verifies the superiority of the HFL-BWM in determining criteria weights;

- The procedure of the HFL-ARAS is proposed, which shows that the ARAS can be employed in the hesitant fuzzy linguistic environment;

- The HFL-BWM and HFL-ARAS are combined under the hesitant fuzzy linguistic environment, making the whole multi-expert MCDM process efficient and applicable;

- The integrated method is implemented to select DSCF suppliers. To a certain extent, this provides a reference for SMEs, especially for the entity manufacturing industry, to select suitable suppliers for financing.

The framework of the paper is organized as follows: In Section 1, we give a literature review on applications of MCDM techniques. Section 2 introduces some related concepts. Section 3 describes the algorithm of the proposed method. In Section 4, a case is given to demonstrate the applicability of the proposed method. The relevant sensitivity analysis and comparative analysis are presented in Section 5. This study closes with some conclusions in last Section.

\section{Literature review on applications of MCDM techniques}

MCDM is usually associated with the task of selecting the best alternative from a limited number of available alternatives, each of which is clearly represented with respect to different decision criteria. There are different MCDM methods proposed by different scholars over the past several decades (Zavadskas \& Turskis, 2010). In view of the increasingly uncertain social environment, a number of researchers developed various fuzzy MCDM methodologies (Mardani et al., 2018), such as the fuzzy TODIM (Tosun \& Akyüz, 2015), fuzzy BWM (Guo \& Zhao, 2017), fuzzy CODAS (COmbinative Distance-based ASsessment) (Keshavarz Ghorabaee, Amiri, Zavadskas, Hooshmand, \& Antuchevičienè, 2017), fuzzy COPRAS (COmplex PRoportional ASsessment) (Zarbakhshnia, Soleimani, \& Ghaderi, 2018) and fuzzy MULTIMOORA (Multi-Objective Optimization on the basis of a Ratio Analysis plus the full MULTIplicative form) (Hafezalkotob, Hafezalkotob, Liao, \& Herrera, 2019a).

Nevertheless, the majority of fuzzy MCDM methodologies were run with either interval numbers or triangular fuzzy numbers to reflect the fuzziness of evaluation information, which inevitably have limitations in information representation. The HFLTS (Rodríguez et al., 2012) is a successful means to reflect the fuzziness and hesitation of the evaluation information as it can be served to express several linguistic terms or comparative linguistic expressions in conjunction with context-free grammar. This method makes it possible to analyze and compute uncertain linguistic expressions, which lays the foundation for decision-making theories and methods to be effectively extended to uncertain environments on the basis of linguistic knowledge (Liao, Xu, Herrera-Viedma, \& Herrera, 2018). On account of linguistic expressions that are more in line with human cognition, the HFLTS can qualitatively express cognition of experts, especially when experts hesitate among several linguistic evaluations 
(Liao et al., 2018). Compared with other methods in which the value range of indeterminacy needs careful consideration, the HFLTS can more flexibly express the hesitation of experts by several linguistic terms. Therefore, this paper takes the hesitant fuzzy linguistic (HFL) evaluations of experts as a base to describe MCDM problems.

At present, many MCDM methods under the HFL environment have been presented, such as the HFL-AHP (Analytic Hierarchy Process) (Tuysuz \& Berna, 2017; Mi et al., 2019b), HFL-BWM (Liao, Mi, Yu, \& Luo, 2019a), HFL-TOPSIS method (Beg, \& Rashid, 2013), HFLCOPRAS method (Zheng, Xu, He, \& Liao, 2018), HFL-VIKOR method (Liao, Xu, \& Zeng, 2015a), and HFL-MABAC (Multi-Attributive Border Approximation area Comparison) method (Sun, Hu, Zhou, \& Chen, 2018). The AHP method is a popular MCDM method which is often used to calculate weights of criteria. As a development of the convention AHP method, the BWM, originally proposed by Rezaei (2015), reduces the times of pairwise comparisons, improves the performance in consistency, and derives the priorities of criteria more efficiently than the AHP method. Guo and Zhao (2017) proposed the fuzzy BWM, which extends the BWM to fuzzy environment. Hafezalkotob, Hafezalkotob, Liao, and Herrera (2019b) investigated the interval-valued BWM for developing the interval MULTIMOORA method. Mou, Xu and Liao (2016) extended the BWM to intuitionistic multiplicative context and used it for group decision making. Stević, Pamučar, Zavadskas, Ćirović, and Prentkovskis (2017) extended the BWM to rough environment, which makes it possible to consider hesitation in the expert evaluation. Liao et al. (2019a) introduced the HFL-BWM, which applies the BWM to hesitant fuzzy linguistic environment, and performances better than the interval BWM, fuzzy BWM and rough BWM in obtaining higher consistent results and normalized weights of criteria. A systematic survey on the state of the art of the BWM and its applications can be found in Mi et al. (2019a).

Up until now, a lot of MCDM techniques have been applied to supplier selection problems. For example, Yu, Shao, Wang and Zhang (2019) used the extended TOPSIS (Technique for Order Performance by Similarity to Ideal Solution) method to select a sustainable supplier. Armin, Mohammad and Mostafa (2018) applied the hybrid BWM-VIKOR (VIsekriterijumska optimizacija i KOmpromisno Resenje) approach for supplier selection in the Iranian agricultural implement industry. Badi and Ballem (2018) employed the rough BWM-MAIRCA (Multi-Attribute Ideal-Real Comparative Analysis) method to select the optimal pharmaceutical supplier. Badi, Abdulshahed and Shetwan (2018) applied the CODAS (COmbinative Distance-based ASsessment) method for supplier selection in steelmaking industry in Libya. Sremac, Stević, Pamučar, Arsić, and Matić (2018) used the rough SWARAWASPAS (Step-Wise Weight Assessment Ratio Analysis-Weighted Aggregated Sum Product Assessment) method for evaluation and selection of third-party logistics suppliers.

In the process of evaluating and selecting suitable suppliers for decision-makers, usually, a complex problem relate to the selection of the best supplier by considering multiple criteria to distinguish the pros and cons of multiple candidate suppliers is raised. In this aspect, the ARAS method (Zavadskas \& Turskis, 2010) can be considered as an appropriate approach to rank the suppliers and determine the optimal one. Compared with other MCDM methods, the ARAS method is an easy-to-understand method, which is characterized by high efficiency and can be easily extended to other environments to solve a great deal of 
practical problems. Since Zavadskas and Turskis (2010) first proposed the ARAS method, it has been extended to various fields to better solve practical problems. The fuzzy ARAS (ARAS-F) method was proposed by Turskis and Zavadskas (2010a). Turskis and Zavadskas (2010b) also proposed the grey ARAS (ARAS-G) method. These two methods enhance the practicability of ARAS method to handle decision-making problems under the incertitude environment. For group decision making problems, Stanujkic, Zavadskas, Karabasevic, Turskis, and Keršulienè (2017) proposed an ARCAS (Additive Ratio Compromise ASsessment) approach, which takes the advantages of both the ARAS and SWARA (step-wise weight assessment ratio analysis) (Keršulienè, Zavadskas, \& Turskis, 2010). The ARAS method has been applied to solve practical problems in various fields, such as the selection of the most suitable and safe foundation instalment alternative in aquifer soil (Turskis, Zavadskas, \& Vilutiene, 2010), the selection of personnel (Karabasevic, Zavadskas, Turskis, \& Stanujkic, 2016), ranking energy development scenarios (Baležentis \& Streimikiene, 2017), evaluating mobile banking services (Ecer, 2018), measuring performance in transportation companies (Radović et al., 2018), and evaluating oil and gas well drilling projects (Dahooie, Zavadskas, Abolhasani, Vanaki, \& Turskis, 2018).

As we can see, few literature combined the ARAS method with weight determination methods of criteria to solve complex and uncertain practical problems effectively in hesitant fuzzy linguistic environment. Hence, starting from the MCDM problem of the DSCF supplier selection, this study dedicates to combining the ARAS method with the BWM to form an efficient and feasible decision-making method under the hesitant fuzzy linguistic environment.

\section{Preliminaries}

\subsection{Hesitant fuzzy linguistic term set}

Rodríguez et al. (2012) proposed the concept of HFLTS, which is an ordered finite subset of the consecutive linguistic terms of a linguistic term set. For better understanding and more widely use, Liao et al. (2015b) redefined the concept of the HFLTS in mathematical form as follows: Let $S=\left\{s_{\alpha} \mid s_{0} \leq s_{\alpha} \leq s_{g}, \alpha \in[0, g]\right\}$ be a linguistic term set. An HFLTS on $X, H_{S}$, is in mathematical terms of $H_{S}=\left\{<x, h_{S}(x)>\mid x \in X\right\}$ where $h_{S}(x)=\left\{s_{\varphi_{l}}(x) \mid s_{\varphi_{l}}(x) \in S, \varphi_{l} \in[0, g], l=1,2, \cdots, L\right\}$ with $L$ being the number of linguistic terms in $h_{S}(x)$ and $s_{\varphi_{l}}(x)(l=1,2, \cdots, L)$ is the continuous terms in $S . h_{S}(x)$ represents a set of possible degrees of the linguistic variable $x$ to $S$ and is termed as the HFLE.

After obtaining the HFLEs, the upper and lower bounds of each HFLE can be obtained and then the HFLE can be denoted by its envelope. The envelope of a HFLE $h_{S}$ is (Rodríguez et al., 2012)

$$
\operatorname{env}\left(h_{S}\right)=\left[h_{S}^{-}, h_{S}^{+}\right] \text {, }
$$

where $h_{S}^{-}$and $h_{S}^{+}$are the minimal and maximal terms in $h_{S}$, respectively.

The transformation rules Martinez and Herrera (Rodríguez et al., 2012) from linguistic expressions to their corresponding HFLEs and envelopes are demonstrated in Table 1 for clear understanding. 
Table 1. The transformation rules from linguistic expressions to HFLEs and their envelopes

\begin{tabular}{|c|l|l|}
\hline & \multicolumn{1}{|c|}{ Transformation rules } & \multicolumn{1}{|c|}{ Envelopes of the HFLEs } \\
\hline TR1 & $\operatorname{TR}_{1}\left(s_{k}\right)=\left\{s_{k} \mid s_{k} \in S\right\}$ & $\operatorname{env}\left(h_{s}\right)=\left[s_{k}, s_{k}\right]$ \\
\hline $\mathrm{TR} 2$ & $\operatorname{TR}_{2}\left(\right.$ greater than $\left.s_{i}\right)=\left\{s_{k} \mid s_{k} \in S\right.$ and $\left.s_{k} \geq s_{i}\right\}$ & $\operatorname{env}\left(h_{s}\right)=\left[s_{i}, s_{\tau}\right]$ \\
\hline $\mathrm{TR} 3$ & $\operatorname{TR}_{3}\left(\right.$ less than $\left.s_{j}\right)=\left\{s_{k} \mid s_{k} \in S\right.$ and $\left.s_{k} \leq s_{j}\right\}$ & $\operatorname{env}\left(h_{s}\right)=\left[s_{-\tau}, s_{j}\right]$ \\
\hline TR4 & $\operatorname{TR}_{4}$ (between $s_{i}$ and $\left.s_{j}\right)=\left\{s_{k} \mid s_{k} \in S\right.$ and $\left.s_{i} \leq s_{k} \leq s_{j}\right\}$ & $\operatorname{env}\left(h_{s}\right)=\left[s_{i}, s_{j}\right]$ \\
\hline
\end{tabular}

$$
\begin{gathered}
\rho\left(h_{S}\right)=\frac{1}{L} \sum_{s_{\varphi_{l}} \in h_{S}} s_{\varphi_{l}}=s_{\frac{1}{L} \sum_{l=1}^{L} \varphi_{l}} ; \\
\sigma\left(h_{S}\right)=\frac{1}{L} \sqrt{\sum_{s_{\varphi_{l}}, s_{\varphi_{k}} \in h_{S}}\left(s_{\varphi_{l}}-s_{\varphi_{k}}\right)^{2}},
\end{gathered}
$$

are the score and variance of the HFLE $h_{S}$, respectively (Liao et al., 2015b). Based on these concepts, Liao et al. (2015a) developed an approach to compare two HFLEs $h_{S}^{1}$ and $h_{S}^{2}$ : if $\rho\left(h_{S}^{1}\right)>\rho\left(h_{S}^{2}\right)$, then $h_{S}^{1}>h_{S}^{2}$; if $\rho\left(h_{S}^{1}\right)=\rho\left(h_{S}^{2}\right)$, then, if $\sigma\left(h_{S}^{1}\right)>\sigma\left(h_{S}^{2}\right)$, then $h_{S}^{1}<h_{S}^{2}$, else if $\sigma\left(h_{S}^{1}\right)=\sigma\left(h_{S}^{2}\right), h_{S}^{1}=h_{S}^{2}$.

For two HFLEs, it is possible that they may have different numbers of linguistic terms. To operate them, a supplementary regulation needs to be done ( $\mathrm{Zhu} \& \mathrm{Xu}, 2014$ ) by adding the term $\bar{s}=\varsigma s^{+}+(1-\varsigma) s^{-}$to the shorter HFLE, where $s^{+}$and $s^{-}$are the maximum and minimum linguistic terms of the shorter HFLE, respectively, and $\varsigma(0 \leq \varsigma \leq 1)$ is a parameter provided by experts according to their risk preferences.

\subsection{Best Worst Method (BWM)}

The BWM is a method to determine weights of criteria, which can reduce the number of comparisons among criteria and has higher consistency compared with AHP. It mainly lets experts give preference information for pairwise comparison between criteria according to the predetermined best and worst criteria, and then establishes a model based on the consistency of preference information to get the weights of criteria.

In the original BWM, the steps to determine the relative importance of criteria are proceed as follows (Rezaei, 2015):

Step 1. Define a set of decision criteria $\left\{c_{1}, c_{2}, \cdots, c_{n}\right\}$.

Step 2. Determine the best criterion $c_{B}$ and the worst criterion $c_{W}$. If more than one criterion is considered to be the best or the worst criterion, a vote can be taken.

Step 3. Make pairwise comparisons between the best criterion over all the other criteria except the best criterion itself, and obtain the Best-to-Others (BO) preference vector $A_{B}=\left[a_{B 1}, a_{B 2}, \cdots, a_{B n}\right]$. Then, make pairwise comparisons between all the other criteria except the best criterion and the worst criterion itself over the worst criterion, and obtain the Others-to-Worst (OW) preference vector $A_{W}=\left[a_{1 W}, a_{2 W}, \cdots, a_{n W}\right]^{T}$. As we can see, all the intensity values in the $\mathrm{BO}$ and $\mathrm{OW}$ preference vectors lie in the interval $[1,9]$, which is different from the values in the AHP which varies between $[1 / 9,9]$. 
Step 4. Obtain weights of criteria. Given that $w_{B} / w_{j}=a_{B j}$ and $w_{j} / w_{W}=a_{j W}$ are the intrinsic consistency properties of the priorities, an optimization model is designed to minimize the maximum absolute differences $\left|w_{B} / w_{j}-a_{B j}\right|$ and $\left|w_{j} / w_{W}-a_{j W}\right|$ for all criteria, shown as follows:

Model 1

$$
\begin{array}{ll}
\min & \xi \\
\text { s.t.: } & \left|w_{B} / w_{j}-a_{B j}\right| \leq \xi, j=1,2, \cdots, n ; \\
& \left|w_{j} / w_{W}-a_{j W}\right| \leq \xi, j=1,2, \cdots, n ; \\
& \sum_{j=1}^{n} w_{j}=1 ; \\
& w_{j} \geq 0, j=1,2, \cdots, n,
\end{array}
$$

where $\xi=\max _{j}\left\{\left|w_{B} / w_{j}-a_{B j}\right|,\left|w_{j} / w_{W}-a_{j W}\right|\right\}$.

Solving Model 1 , the optimal weight vector $\left\{w_{1}^{*}, \cdots, w_{j}^{*}, \cdots, w_{n}^{*}\right\}$ and the maximum absolute difference $\xi^{*}$ can be obtained.

\subsection{Additive Ratio ASsessment (ARAS)}

In the ARAS method, the utility value that determines an alternative's relative complex efficiency is in proportion to the relative impact of criteria weights considered in the problem. The ARAS method to solve MCDM problems can be implemented in the following steps (Zavadskas \& Turskis, 2010):

Step 1. Establish a decision matrix $X=\left(x_{i j}\right)_{m \times n}$ where $x_{i j}$ represents the performance of the $i$ th alternative with respect to the $j$ th criterion, $x_{0 j}$ is the optimal value of the $j$ th criterion, $i=0,1, \cdots, m, j=1,2, \cdots, n$. If the optimal value of the $j$ th criterion is unknown, then,

$$
x_{0 j}=\left\{\begin{array}{l}
\max _{i} x_{i j}, \text { for benefit criterion } \\
\min _{i} x_{i j}, \text { for cost criterion }
\end{array} .\right.
$$

Step 2. Compute the normalized decision matrix $\bar{X}=\left(\bar{x}_{i j}\right)_{m \times n}$, where

$$
\bar{x}_{i j}=\left\{\begin{array}{l}
\frac{x_{i j}}{\sum_{i=0}^{m} x_{i j}}, \text { for benefit type criterion } \\
\frac{1 / x_{i j}}{\sum_{i=0}^{m} 1 / x_{i j}}, \text { for cost type criterion }
\end{array}\right.
$$

Step 3. Compute the weighted normalized decision matrix $\hat{X}=\left(\hat{x}_{i j}\right)_{m \times n}$, where $\hat{x}_{i j}$ is calculated by multiplying the normalized value $\bar{x}_{i j}$ with the weight $w_{j} \times n$ of criterion $c_{j}$, i.e., $\hat{x}_{i j}=w_{j} \bar{x}_{i j}$.

Step 4. Calculate the optimal value of each alternative by $S_{i}=\sum_{j=1}^{n} \hat{x}_{i j}$, for $i=0,1, \cdots, m$.

Step 5. Calculate the utility degree of each alternative by $K_{i}=S_{i} / S_{0}$, for $i=0,1, \cdots, m$.

Step 6. The alternatives are ranked in descending order of the value of $K_{i}(i=1,2, \cdots, m)$. The alternative $A_{i}$ that has the highest value of $K_{i}$ is regarded as the best alternative. 


\section{An integrated multi-expert MCDM method based on the HFL-BWM and HFL-ARAS}

A typical multi-expert MCDM problem often consists of a finite number of alternatives, a set of different criteria, and a group of experts who are invited to evaluate these alternatives with respect to the criteria, and then, the evaluation information from these experts is integrated to determine the ranking of alternatives. To make the multi-expert MCDM process as efficient as possible, in this section, an integrated multi-expert MCDM method is proposed based on the HFL-BWM and the HFL-ARAS. The HFL-BWM is applied to obtain the weights of criteria while the ARAS method is extended to the HFL environment to obtain the ranking of alternatives.

\subsection{Determine the weights of criteria for multi-expert MCDM problems by the HFL-BWM}

In this subsection, inspired by the idea of the HFL-BWM proposed by Liao et al. (2019a), we study how to determine the weights of criteria for multi-expert MCDM problems.

Experts $\left\{D_{1}, D_{2}, \cdots, D_{k}, \cdots, D_{e}\right\}$ are required to select the most important and the least important criteria from the set of criteria $\left\{c_{1}, c_{2}, \cdots, c_{j}, \cdots, c_{n}\right\}$ regarding the predetermined objective. The best and the worst criteria selected by each expert are represented as $c_{B}^{D_{k}}$ and $c_{W}^{D_{k}}$, respectively. Then, the experts are asked to make pairwise comparisons between $c_{B}^{D_{k}}$ and all other criteria based on an appropriate linguistic term set, and obtain the HFLBO preference vectors $\left(H_{S}^{B}\right)^{D_{k}}=\left(\left(h_{S}^{B 1}\right)^{D_{k}},\left(h_{S}^{B 2}\right)^{D_{k}}, \cdots,\left(h_{S}^{B n}\right)^{D_{k}}\right)$, for $k=1,2, \cdots, e$. Likewise, the experts are also asked to make pairwise comparisons between all other criteria and $c_{W}^{D_{k}}$, and get the HFL-OW preference vectors $\left(H_{S}^{W}\right)^{D_{k}}=\left(\left(h_{S}^{1 W}\right)^{D_{k}},\left(h_{S}^{2 W}\right)^{D_{k}}, \cdots,\left(h_{S}^{n W}\right)^{D_{k}}\right)^{T}$, for $k=1,2, \cdots, e$. Initially, the pairwise comparison values of the preference vectors are flexibly represented by linguistic expressions. Based on the transformation rules given in Table 1, we can transfer these values into HFLEs. For the facility of further computation, we can transfer the HFLEs to their envelops by Eq. (1), and thus get two preference vectors env $v^{D_{k}}\left(H_{S}^{B}\right)=\left[e n v^{D_{k}}\left(h_{S}^{B 1}\right), e n v^{D_{k}}\left(h_{S}^{B 2}\right), \cdots, e n v^{D_{k}}\left(h_{S}^{B n}\right)\right]$ and $e n v^{D_{k}}\left(H_{S}^{W}\right)=\left[e n v^{D_{k}}\left(h_{S}^{1 W}\right), e n v^{D_{k}}\left(h_{S}^{2 W}\right), \cdots, e n v^{D_{k}}\left(h_{S}^{n W}\right)\right]^{T}$, respectively.

Because different experts may have different cognitive standard towards the MCDM problem, it is unrealistic to use a specific parameter to measure the objective ratio of two adjacent terms for all experts. Let $a$ be the objective importance ratio of two adjacent terms. Based on the linguistic term set used for comparing criteria, the value of $a$ can be determined by (Liao et al. 2019a):

$$
a=\sqrt[g]{\text { best/worst }}
$$

where best/worst is provided by the expert, representing the greatest difference in the expert's evaluation information. $g$ stands for the number of linguistic terms in the linguistic term set.

Then, we can construct the model as follows (Liao et al. 2019a): 
Model 2

$$
\begin{array}{ll}
\min & \xi \\
\text { s.t.: } & \left|w_{B}^{D_{k}-} / w_{j}^{D_{k}-}-U^{-}\left(e n v^{D_{k}}\left(h_{S}^{B j}\right)\right)\right| \leq \xi ; \\
& \left|w_{B}^{D^{+}} / w_{j}^{D^{+}}-U^{+}\left(e n v^{D_{k}}\left(h_{S}^{B j}\right)\right)\right| \leq \xi ; \\
& \left|w_{j}^{D_{k}-} / w_{W}^{D_{k}-}-U^{-}\left(e n v^{D_{k}}\left(h_{S}^{j W}\right)\right)\right| \leq \xi ; \\
& \left|w_{j}^{D^{+}} / w_{W}^{D^{+}}-U^{+}\left(e n v^{D_{k}}\left(h_{S}^{j W}\right)\right)\right| \leq \xi ; \\
& \sum_{\delta=1, \delta \neq j}^{n} w_{\delta}^{D_{k^{+}}}+w_{j}^{D_{k}-} \geq 1 ; \\
& \sum_{\delta=1, \delta \neq j}^{n} w_{\delta}^{D_{k}-}+w_{j}^{D_{k}+} \leq 1 ; \\
& w_{j}^{+} \geq w_{j}^{-} \geq 0, j=1,2, \cdots, n,
\end{array}
$$

where $\sum_{\delta=1, \delta \neq j}^{n} w_{\delta}^{D_{k^{+}}}+w_{j}^{D_{k^{-}}} \geq 1$ and $\sum_{\delta=1, \delta \neq j}^{n} w_{\delta}^{D_{k^{-}}}+w_{j}^{D^{+}} \leq 1$ are the constraints of interval weights (Sugihara, Ishii \& Tanaka, 2004). $U^{-}\left(\operatorname{env}\left(h_{S}\right)\right)=U\left(h_{S}^{-}\right)=a^{\beta}$ and $U^{+}\left(e n v\left(h_{S}\right)\right)=$ $U\left(h_{S}^{+}\right)=a^{\gamma}$. Here $\beta$ and $\gamma$ are the subscripts of the minimal term $h_{S}^{-}$and the maximal term $h_{S}^{+}$in $h_{S}$, respectively.

Solving Model 2, we can obtain the optimal interval weight vectors of criteria with respect to each expert, $w^{D_{k}{ }^{*}}=\left(\left[w_{1}^{D_{k}^{-} \star}, w_{1}^{D_{k}{ }^{+}}\right],\left[w_{2}^{D_{k}^{-\star}}, w_{2}^{D_{k}{ }^{+}}\right], \cdots,\left[w_{n}^{D^{-}{ }^{-}}, w_{n}^{D_{k}{ }^{+}}\right]\right)^{T}$, and the minimum absolute difference $\xi^{*}$. As we can see, when $\xi^{*}=0$, the pairwise comparisons are supposed to be consistent. In this sense, $\xi^{*}$ can be regarded as a consistency measure. The consistency ratio (CR) of the pairwise comparisons can be computed by:

$$
C R=\xi^{*} / C I,
$$
where the consistency index $C I=\xi^{\max }=\frac{2 \times U^{+}\left(\operatorname{env}\left(h_{S}^{B W}\right)\right)+1-\sqrt{8 \times U^{+}\left(\operatorname{env}\left(h_{S}^{B W}\right)\right)-1}}{2}$
(Liao et al. 2019a).

The limited value of CR can be subjectively determined by the decision-making committee. It is generally true that as long as CR is less than or equal to $0.1, \mathrm{CR}$ is considered to be acceptable. By contrast, if the CR is greater than 0.1 , the pairwise comparison values given by the expert are supposed to be inconsistent, that is, CR is not accepted, and the expert's opinions need to be collected again.

Next, the priorities of criteria with respect to all experts can be integrated by the interval weighed geometric aggregation (IWGA) operator (Xu, 2013):

$$
w_{j}^{*}=\operatorname{IWGA}\left(w_{j}^{D_{1}^{*}}, w_{j}^{D_{2}}, \cdots, w_{j}^{D_{e}^{*}}\right)=\left[\prod_{k=1}^{e}\left(w_{j}^{D^{-*}}\right)^{\lambda_{k}}, \prod_{k=1}^{e}\left(w_{j}^{D_{k}^{+*}}\right)^{\lambda_{k}}\right] \text {, for } j=1,2, \cdots, n \text {, }
$$

where $\lambda_{k}$ is the relative importance of expert $D_{k}$, with $\lambda_{k} \in[0,1]$ and $\sum_{k=1}^{e} \lambda_{k}=1$.

The comprehensive weight of each criterion, $\bar{w}_{j}$, can be obtained by taking the intermediate value of the integrated interval values, i.e.,

$$
\bar{w}_{j}=\left(\prod_{k=1}^{e}\left(w_{j}^{D_{k}^{-*}}\right)^{\lambda_{k}}+\prod_{k=1}^{e}\left(w_{j}^{D_{k}^{+^{*}}}\right)^{\lambda_{k}}\right) / 2 \text {, for } j=1,2, \cdots, n .
$$


Finally, the normalized weight of each criterion can be obtained to make the sum of the weights equal to 1 , i.e.:

$$
w_{j}=\bar{w}_{j} / \sum_{j=1}^{n} \bar{w}_{j}, \text { for } j=1,2, \cdots, n
$$

\subsection{Rank the alternatives by the HFL-ARAS}

Experts are required to evaluate alternatives $\left\{A_{1}, A_{2}, \cdots, A_{i}, \cdots, A_{m}\right\}$ over each criterion referring to an appropriate linguistic term set. Because it is possible that experts may hesitate among several linguistic terms in the process of evaluation, the linguistic expressions are formed by taking into account several linguistic term sets that experts hesitate to use. Then, these linguistic expressions can be transformed to HFLEs and the HFL decision matrices can be obtained as:

$$
H_{S}^{D_{k}}=\left(\begin{array}{cccccc}
h_{S}^{D_{k}}\left(x_{01}\right) & h_{S}^{D_{k}}\left(x_{02}\right) & \cdots & h_{S}^{D_{k}}\left(x_{0 j}\right) & \cdots & h_{S}^{D_{k}}\left(x_{0 n}\right) \\
h_{S}^{D_{k}}\left(x_{11}\right) & h_{S}^{D_{k}}\left(x_{12}\right) & \cdots & h_{S}^{D_{k}}\left(x_{1 j}\right) & \cdots & h_{S}^{D_{k}}\left(x_{1 n}\right) \\
\vdots & \vdots & \ddots & \vdots & \ddots & \vdots \\
h_{S}^{D_{k}}\left(x_{i 1}\right) & h_{S}^{D_{k}}\left(x_{i 2}\right) & \cdots & h_{S}^{D_{k}}\left(x_{i j}\right) & \cdots & h_{S}^{D_{k}}\left(x_{i n}\right) \\
\vdots & \vdots & \ddots & \vdots & \ddots & \vdots \\
h_{S}^{D_{k}}\left(x_{m 1}\right) & h_{S}^{D_{k}}\left(x_{m 2}\right) & \cdots & h_{S}^{D_{k}}\left(x_{m j}\right) & \cdots & h_{S}^{D_{k}}\left(x_{m n}\right)
\end{array}\right) \text {, for } k=1,2, \cdots, e,
$$

where $h_{S}^{D_{k}}\left(x_{i j}\right)$ is an HFLE, expressing the performance of alternative $A_{i}$ over criterion $c_{j}$ with regard to expert $D_{k}$. The initial HFLEs can be transferred for calculation by the supplementary regulation presented in Section 3.1.

When experts have no preferences, for the benefit criterion, the ideal evaluation is:

$$
h_{S}^{D_{k}}\left(x_{0 j}\right)=\max _{i} h_{S}^{D_{k}}\left(x_{i j}\right) .
$$

For the cost criterion, the ideal evaluation is:

$$
h_{S}^{D_{k}}\left(x_{0 j}\right)=\min _{i} h_{S}^{D_{k}}\left(x_{i j}\right) \text {. }
$$

Then, we determine the normalized HFL decision matrix $\bar{H}_{S}$ as:

where

$$
\bar{H}_{S}^{D_{k}}=\left(\begin{array}{cccccc}
\bar{h}_{S}^{D_{k}}\left(x_{01}\right) & \bar{h}_{S}^{D_{k}}\left(x_{02}\right) & \cdots & \bar{h}_{S}^{D_{k}}\left(x_{0 j}\right) & \cdots & \bar{h}_{S}^{D_{k}}\left(x_{0 n}\right) \\
\bar{h}_{S}^{D_{k}}\left(x_{11}\right) & \bar{h}_{S}^{D_{k}}\left(x_{12}\right) & \cdots & \bar{h}_{S}^{D_{k}}\left(x_{1 j}\right) & \cdots & \bar{h}_{S}^{D_{k}}\left(x_{1 n}\right) \\
\vdots & \vdots & \ddots & \vdots & \ddots & \vdots \\
\bar{h}_{S}^{D_{k}}\left(x_{i 1}\right) & \bar{h}_{S}^{D_{k}}\left(x_{i 2}\right) & \cdots & \bar{h}_{S}^{D_{k}}\left(x_{i j}\right) & \cdots & \bar{h}_{S}^{D_{k}}\left(x_{i n}\right) \\
\vdots & \vdots & \ddots & \vdots & \ddots & \vdots \\
\bar{h}_{S}^{D_{k}}\left(x_{m 1}\right) & \bar{h}_{S}^{D_{k}}\left(x_{m 2}\right) & \cdots & \bar{h}_{S}^{D_{k}}\left(x_{m j}\right) & \cdots & \bar{h}_{S}^{D_{k}}\left(x_{m n}\right)
\end{array}\right) \text {, for } k=1,2, \cdots, e,
$$

$$
\begin{aligned}
& \bar{h}_{S}^{D_{k}}\left(x_{i j}\right)=\left\{s_{\varphi_{l}}\left(x_{i j}\right) \mid s_{\varphi_{l}}\left(x_{i j}\right) \in h_{S}^{D_{k}}\left(x_{i j}\right)\right\} \text {, for benefit criterion; } \\
& \overline{\sum_{i=1}^{m} \varphi_{l}} \\
& \bar{h}_{S}^{D_{k}}\left(x_{i j}\right)=\left\{s_{1 / \varphi_{l}}^{\sum_{i=1}}\left(x_{i j}\right) \mid s_{\varphi_{l}}\left(x_{i j}\right) \in h_{S}^{D_{k}}\left(x_{i j}\right)\right\} \text {, for cost criterion. } \\
& \overline{\sum_{i=1}^{m} 1 / \varphi_{l}}
\end{aligned}
$$


Afterward, we use the GHFLWA (generalized hesitant fuzzy linguistic weighted averaging) operator (Zhang \& Wu, 2014) to aggregate the individual hesitant fuzzy linguistic decision matrices to a collective one such as:

$$
H_{S}=\left(\begin{array}{cccccc}
h_{S}\left(x_{01}\right) & h_{S}\left(x_{02}\right) & \cdots & h_{S}\left(x_{0 j}\right) & \cdots & h_{S}\left(x_{0 n}\right) \\
h_{S}\left(x_{11}\right) & h_{S}\left(x_{12}\right) & \cdots & h_{S}\left(x_{1 j}\right) & \cdots & h_{S}\left(x_{1 n}\right) \\
\vdots & \vdots & \ddots & \vdots & \ddots & \vdots \\
h_{S}\left(x_{i 1}\right) & h_{S}\left(x_{i 2}\right) & \cdots & h_{S}\left(x_{i j}\right) & \cdots & h_{S}\left(x_{i n}\right) \\
\vdots & \vdots & \ddots & \vdots & \ddots & \vdots \\
h_{S}\left(x_{m 1}\right) & h_{S}\left(x_{m 2}\right) & \cdots & h_{S}\left(x_{m j}\right) & \cdots & h_{S}\left(x_{m n}\right)
\end{array}\right)
$$

where

$$
\begin{aligned}
h_{S}\left(x_{i j}\right)= & \operatorname{GHFLWA} A_{\ddot{e}}\left(\bar{h}_{S}^{D_{1}}\left(x_{i j}\right), \bar{h}_{S}^{D_{2}}\left(x_{i j}\right), \cdots, \bar{h}_{S}^{D_{e}}\left(x_{i j}\right)\right)=\left(\bigoplus_{k=1}^{e}\left(\lambda_{k} \bar{h}_{S}^{D_{k}}\left(x_{i j}\right)^{\mu}\right)\right)^{1 / \mu}= \\
& \left.\bigcup_{s_{\varphi l}^{D_{1}}\left(x_{i j}\right) \in \bar{h}_{S}^{D_{1}}\left(x_{i j}\right), s_{\varphi l}^{D_{2}}\left(x_{i j}\right) \in \bar{h}_{S}^{D_{2}}\left(x_{i j}\right), \cdots, s_{\varphi l}^{D_{e}}\left(x_{i j}\right) \in \bar{h}_{S}^{D_{e}}\left(x_{i j}\right)}^{\{s}\left(\sum_{k=1}^{e} \lambda_{k} s_{\varphi l}^{D_{k}}\left(x_{i j}\right)^{\mu}\right)^{1 / \mu}\right\}, \mu \in[0,1] .
\end{aligned}
$$

Next, we can calculate the weighted normalized HFL decision matrix as:

$$
\hat{H}_{S}=\left[\begin{array}{cccccc}
\hat{h}_{S}\left(x_{01}\right) & \hat{h}_{S}\left(x_{02}\right) & \cdots & \hat{h}_{S}\left(x_{0 j}\right) & \cdots & \hat{h}_{S}\left(x_{0 n}\right) \\
\hat{h}_{S}\left(x_{11}\right) & \hat{h}_{S}\left(x_{12}\right) & \cdots & \hat{h}_{S}\left(x_{1 j}\right) & \cdots & \hat{h}_{S}\left(x_{1 n}\right) \\
\vdots & \vdots & \ddots & \vdots & \ddots & \vdots \\
\hat{h}_{S}\left(x_{i 1}\right) & \hat{h}_{S}\left(x_{i 2}\right) & \cdots & \hat{h}_{S}\left(x_{i j}\right) & \cdots & \hat{h}_{S}\left(x_{i n}\right) \\
\vdots & \vdots & \ddots & \vdots & \ddots & \vdots \\
\hat{h}_{S}\left(x_{m 1}\right) & \hat{h}_{S}\left(x_{m 2}\right) & \cdots & \hat{h}_{S}\left(x_{m j}\right) & \cdots & \hat{h}_{S}\left(x_{m n}\right)
\end{array}\right],
$$

where $\hat{h}_{S}\left(x_{i j}\right)$ can be computed by:

$$
\hat{h}_{S}\left(x_{i j}\right)=w_{j} h_{S}\left(x_{i j}\right)
$$

with $w_{j}$ being criterion weight calculated by Eq. (8).

Then, we can determine the overall performance of alternative $A_{i}$ by:

$$
\tilde{P}_{i}=\bigoplus_{j=1}^{n} \hat{h}_{S}\left(x_{i j}\right)=\left\{s_{\sum_{l=1}^{L} \varphi_{l}} \mid s_{\varphi_{l}} \in \hat{h}_{S}\left(x_{i j}\right)\right\} .
$$

The mean value of $P_{i}$ can be obtained by calculating the average of the subscripts of the linguistic terms in $\tilde{P}_{i}$.

To check which alternative is closest to the ideal one, the utility degree $Q_{i}$ of alternative $A_{i}$ can be calculated by comparing the mean value $P_{i}$ of each alternative with the mean value $P_{0}$ of the ideal alternative, shown as:

$$
Q_{i}=P_{i} / P_{0}
$$

Finally, rank the alternatives in descending order of $Q_{i}(i=1,2, \cdots, m)$, and ascertain the optimal alternative by the following equation ( $\mathrm{Liao}, \mathrm{Fu}, \& \mathrm{Wu}, 2016$ ):

$$
A_{i}^{*}=\left\{A_{i} \mid \max _{i} Q_{i}\right\}
$$




\subsection{Procedure of the HFL-BWM-ARAS method for multi-expert MCDM}

To make the proposed multi-expert MCDM method understandable, the procedure of the proposed HFL-BWM-ARAS by combining the HFL-BWM and the HFL-ARAS is given concisely as follows:

Step 1. Convene a decision-making committee of experts $\left\{D_{1}, D_{2}, \cdots, D_{k}, \cdots, D_{e}\right\}$, and determine an objective, $n$ criteria $\left\{c_{1}, c_{2}, \cdots, c_{j}, \cdots, c_{n}\right\}$ and $m$ alternatives $\left\{A_{1}, A_{2}, \cdots, A_{i}, \cdots, A_{m}\right\}$ for a multi-expert MCDM problem.

Step 2. Find the best criterion $c_{B}^{D_{k}}$ and the worst criterion $c_{W}^{D_{k}}$. Then, compare $c_{B}^{D_{k}}$ with all other criteria, respectively, and also compare all other criteria with $c_{W}^{D_{k}}$, respectively. The pairwise comparison information is represented by linguistic expressions and then transformed to HFLEs and their envelops by Table 1.

Step 3. Derive the interval weight vector of criteria $w^{D_{k}^{*}}=\left(\left[w_{1}^{D_{k}{ }^{-*}}, w_{1}^{D_{k}{ }^{+} *}\right],\left[w_{2}^{D_{k^{-}}}, w_{2}^{D_{k^{+}}}\right]\right.$, $\cdots,\left[w_{n}^{D_{k^{-*}}}, w_{n}^{\left.\left.D^{{ }^{+} *}\right]\right)^{T}}\right.$ and the minimum absolute difference $\xi^{*}$ for each expert by Model 2 . Then compute the consistency ratio by Eq. (5). If all the experts' pairwise comparisons pass the consistency checking condition, then go to the next step; otherwise, we should ask the expert whose consistency is low to reevaluate the criteria.

Step 4. Obtain the normalization weight vector of criteria by Eqs (6)-(8).

Step 5. Determine the HFL decision matrix $H_{S}^{D_{k}}$ and ascertain the optimal performance ratings for each expert by Eqs (9) and (10). Then, calculate the weighted normalized HFL decision matrix $\hat{H}_{S}$ by Eqs (11)-(14).

Step 6. Calculate the utility degree $Q_{i}$ of each alternative by Eq. (16), and find the optimal alternative by Eq. (17).

The first step of the above procedure determines the basic information involved in the multi-expert MCDM problem. The second step determines the best and worst criteria for each expert, and establishes the preference vectors by comparing the best and worst criteria with all other criteria, respectively. The third step derives the interval weights of the criteria evaluated by each expert based on the optimization model constructed by preference vectors, and then check the consistency ratio of the pairwise comparisons given by each expert. If the evaluation information of an expert does not pass the consistency checking process, we need to collect the expert's pairwise comparison information again. The fourth step determine the normalized weight of each criterion according to the optimal interval weights of criteria evaluated by each expert. The fifth step determines the HFL decision matrices, and integrates these matrices given by the experts to a normalized weighted HFL decision matrix based on the criteria weights obtained in the fourth step. The last step calculates the utility value of each alternative and rank the alternatives according to the utility values. In this procedure, steps 2-4 belong to the HFL-BWM while steps 5-6 belong to the HFL-ARAS method. 


\section{Case study: Selecting suitable DSCF supplier for SMEs}

Selecting an appropriate DSCF supplier for financing has a vital impact on the development of most SMEs. This section presents a case study about DSCF supplier selection. The proposed multi-expert MCDM method is applied to solve the case.

\subsection{Case description}

The financing needs of SMEs in China's entity manufacturing industry generally have the characteristics of high frequency, small amount of capital, short cycle and large randomness. In addition, due to the strong competitiveness of core enterprises, they are in a strong position in negotiation with SMEs upstream and downstream in the manufacturing industry. To reduce costs, SMEs upstream and downstream in the manufacturing industry are often demanded in terms of delivery, price and account period, such as lower discounts, longer credit period and shorter delivery time, which cause a huge burden to SMEs in the manufacturing industry. Therefore, most of these enterprises have problems with financing difficulties and high financing costs, which seriously restricts the further development of enterprises. A new financing mode is urgently needed to solve these problems for SMEs. The DSCF, as a new financial technology means, compensates for risk through the evaluation and control of advance payment, inventory and receivables. Its goal is to improve the internal capital efficiency of manufacturing supply chain and enhance the competitiveness of the whole supply chain. Compared with bank credit model, the DSCF is more inclusive for SMEs in manufacturing industry. The DSCF is no longer confined to the individual evaluation of SMEs in manufacturing industry, but more focused on the evaluation of core enterprises. On the basis of the whole industrial chain, DSCF conducts the overall credit evaluation of the participants in the manufacturing supply chain and relaxes the financing access threshold of SMEs in manufacturing industry. This provides conditions for most SMEs to choose suitable suppliers on their own initiative.

$\mathrm{R}$ company is a private limited liability company which mainly produces biscuits, cakes, bread and other leisure food series in China. At present, its employees are about 80 people and its business income is more than 5 million RMB (This relatively small scale of personnel and operation is recognized as a SME in China). Based on the above background and due to the small scale of operation and opaque finance, R company, as a SME in entity manufacturing industry, often faces the situation of financing difficulties, which seriously affects the further development of the company. For expanding reproduction, improving the efficiency of internal capital operation, and thus enhancing the competitiveness of the entire industrial chain, $\mathrm{R}$ company decided to seek a suitable DSCF supplier.

The decision-making group of $\mathrm{R}$ company consisted of four members: the chief executive officer $\left(D_{1}\right)$, the general manager $\left(D_{2}\right)$, and two experts $\left(D_{3}, D_{4}\right)$ with rich experience in DSCF supplier evaluation problems. The weight vector of the group members is $w=(0.4,0.1,0.3,0.2)^{T}$. The company needs to select the most suitable DSCF supplier from four suitable suppliers $\left(A_{1}, A_{2}, A_{3}, A_{4}\right)$. In addition, the evaluation criteria $\left(c_{1}, c_{2}, c_{3}, c_{4}, c_{5}, c_{6}, c_{7}\right)$ are presented in Table 2. 
Table 2. The criteria for evaluation over the candidate DSCF suppliers

\begin{tabular}{|l|l|c|}
\hline \multicolumn{1}{|c|}{ Criterion } & \multicolumn{1}{|c|}{ Sub-criterion } & Form \\
\hline \multirow{4}{*}{ Digital competence } & Digital engagement $\left(c_{1}\right)$ & Benefit \\
\cline { 2 - 3 } & Scale of digital collaboration $\left(c_{2}\right)$ & Benefit \\
\cline { 2 - 3 } & Degree of information sharing $\left(c_{3}\right)$ & Benefit \\
\hline \multirow{2}{*}{ Customer centricity } & Service quality $\left(c_{4}\right)$ & Benefit \\
\cline { 2 - 3 } & Flexibility $\left(c_{5}\right)$ & Benefit \\
\hline \multirow{2}{*}{ Financing capacity } & Financing efficiency $\left(c_{6}\right)$ & Benefit \\
\cline { 2 - 3 } & Financing threshold $\left(c_{7}\right)$ & Cost \\
\hline
\end{tabular}

Among these criteria, digital engagement $\left(c_{1}\right)$, scale of digital collaboration $\left(c_{2}\right)$, and degree of information sharing $\left(c_{2}\right)$, are the criteria for expressing the digital level of suppliers, which are displayed based on the criteria proposed by Büyüközkan and Göcer (2018) for the selection of suitable digital suppliers. Service quality $\left(c_{4}\right)$ refers to the degree to which the service can meet the needs of recipients. Flexibility $\left(c_{5}\right)$ refers to the ability to make changes when unexpected situations arise in the service process. Criteria $c_{4}$ and $c_{5}$ are proposed by the chief executive officer and general manager of the $\mathrm{R}$ company to consider the service performance of suppliers. Financing efficiency $\left(c_{6}\right)$ is a comprehensive consideration of the corresponding maximum amount of financing for SMEs and the time required for the process. Financing threshold $\left(c_{7}\right)$ mainly refers to the requirements of suppliers for SMEs in all aspects. Criteria $c_{6}$ and $c_{7}$ are proposed by two experts with rich experience in DSCF supplier evaluation problems to consider the financing performance of suppliers.

\subsection{Select the optimal supplier by the proposed multi-expert MCDM method}

The specific steps of using the proposed multi-expert MCDM model to solve the decisionmaking problem of selecting the suitable DSCF supplier are as follows:

Step 1. Based on the information with respect to the multi-expert MCDM problem given in Section 5.1, the candidate suppliers, evaluation criteria, experts and their weights were given.

Step 2. The best and the worst criteria are selected by experts. For example, according to selection of $\mathrm{D}_{4}$, the most important criterion is financing threshold $\left(c_{7}\right)$ and scale of digital collaboration $\left(c_{2}\right)$ is the least important one. Then, experts are asked to make pairwise comparisons between the important criteria and all other criteria based on the following linguistic term set (Abdullah \& Najib, 2016):

$$
\left\{\begin{array}{l}
I_{0}: \text { equally important, } I_{1}: \text { equally very important, } I_{2}: \text { moderately important, } \\
I_{3}: \text { moderately more important, } I_{4}: \text { strongly important, } \\
I_{5}: \text { strongly more important, } I_{6}: \text { very strongly more important, } \\
I_{7}: \text { extremely strong important, } I_{8}: \text { extremely more important }
\end{array}\right\} \text {. }
$$

Taking the evaluation of $\mathrm{D}_{4}$ as an example, $\mathrm{D}_{4}$ hesitates between "extremely strong important" and "extremely more important" when comparing $c_{7}$ with $c_{2}$, and then preference 
degree of $c_{7}$ over $c_{2}$ can be expressed by env $\left(h_{I}^{B W}\right)=\left[I_{8}, I_{9}\right]$. In this way, the HFL-BO preference vector of $\mathrm{D}_{4}$ can be obtained as: $\operatorname{env}\left(H_{I}^{B 4}\right)=\left(\left[I_{5}\right],\left[I_{7}, I_{8}\right],\left[I_{6}, I_{7}\right],\left[I_{2}\right],\left[I_{3}, I_{4}\right],\left[I_{1}\right],\left[I_{0}\right]\right)$. Likewise, $\mathrm{D}_{4}$ is asked to make pairwise comparisons between all other criteria and the least important criteria $\left(c_{2}\right)$, and the HFL-OW preference vector can be obtained as: $\operatorname{env}\left(H_{I}^{W 4}\right)=\left(\left[I_{2}\right],\left[I_{0}\right],\left[I_{1}, I_{2}\right],\left[I_{5}\right],\left[I_{4}, I_{5}\right],\left[I_{6}\right],\left[I_{7}, I_{8}\right]\right)^{T}$.

In analogous, we have

$$
\begin{aligned}
& c_{B}^{1}=c_{7}, c_{W}^{1}=c_{3}, \operatorname{env}\left(H_{I}^{B 1}\right)=\left(\left[I_{3}\right],\left[I_{4}, I_{5}\right],\left[I_{8}\right],\left[I_{1}, I_{2}\right],\left[I_{6}, I_{7}\right],\left[I_{2}\right],\left[I_{0}\right]\right), \\
& \operatorname{env}\left(H_{I}^{W 1}\right)=\left(\left[I_{4}\right],\left[I_{3}, I_{4}\right],\left[I_{0}\right],\left[I_{6}, I_{7}\right],\left[I_{1}, I_{2}\right],\left[I_{5}\right],\left[I_{8}\right]\right)^{T} ; \\
& c_{B}^{2}=c_{4}, c_{W}^{2}=c_{6}, \operatorname{env}\left(H_{I}^{B 2}\right)=\left(\left[I_{3}, I_{4}\right],\left[I_{6}\right],\left[I_{4}, I_{5}\right],\left[I_{0}\right],\left[I_{6}, I_{7}\right],\left[I_{8}\right],\left[I_{1}, I_{2}\right]\right), \\
& \operatorname{env}\left(H_{I}^{W 2}\right)=\left(\left[I_{4}, I_{5}\right],\left[I_{2}\right],\left[I_{3}, I_{4}\right],\left[I_{8}\right],\left[I_{1}, I_{2}\right],\left[I_{0}\right],\left[I_{5}, I_{6}\right]\right)^{T} ; \\
& c_{B}^{3}=c_{1}, c_{W}^{3}=c_{5}, \operatorname{env}\left(H_{I}^{B 3}\right)=\left(\left[I_{0}\right],\left[I_{6}\right],\left[I_{2}\right],\left[I_{3}, I_{4}\right],\left[I_{7}, I_{8}\right],\left[I_{5}, I_{6}\right],\left[I_{1}\right]\right), \\
& \operatorname{env}\left(H_{I}^{W 3}\right)=\left(\left[I_{7}, I_{8}\right],\left[I_{1}\right],\left[I_{5}\right],\left[I_{4}, I_{5}\right],\left[I_{0}\right],\left[I_{1}, I_{2}\right],\left[I_{6}\right]\right)^{T} .
\end{aligned}
$$

The value of best/worst given by the experts is 9. Thus, using Eq. (4), we have $a=\sqrt[8]{9}=1.316$.

Step 3. According to Model 2 in Section 3.1, the optimization model for criterion weights with respect to $\mathrm{D}_{4}$ can be constructed as Model:

Model 3

$$
\begin{array}{ll}
\min & \xi \\
\text { s.t.: } & \left|w_{7}^{-} / w_{1}^{-}-a^{5}\right| \leq \xi,\left|w_{7}^{+} / w_{1}^{+}-a^{5}\right| \leq \xi ; \\
& \left|w_{7}^{-} / w_{2}^{-}-a^{7}\right| \leq \xi,\left|w_{7}^{+} / w_{2}^{+}-a^{8}\right| \leq \xi ; \\
& \left|w_{7}^{-} / w_{3}^{-}-a^{6}\right| \leq \xi,\left|w_{7}^{+} / w_{3}^{+}-a^{7}\right| \leq \xi ; \\
& \left|w_{7}^{-} / w_{4}^{-}-a^{2}\right| \leq \xi,\left|w_{7}^{+} / w_{4}^{+}-a^{2}\right| \leq \xi ; \\
& \left|w_{7}^{-} / w_{5}^{-}-a^{3}\right| \leq \xi,\left|w_{7}^{+} / w_{5}^{+}-a^{4}\right| \leq \xi ; \\
& \left|w_{7}^{-} / w_{6}^{-}-a^{1}\right| \leq \xi,\left|w_{7}^{+} / w_{6}^{+}-a^{1}\right| \leq \xi ; \\
& \left|w_{7}^{-} / w_{7}^{-}-a^{0}\right| \leq \xi,\left|w_{7}^{+} / w_{7}^{+}-a^{0}\right| \leq \xi ; \\
& \left|w_{1}^{-} / w_{2}^{-}-a^{2}\right| \leq \xi,\left|w_{1}^{+} / w_{2}^{+}-a^{2}\right| \leq \xi ; \\
& \left|w_{2}^{-} / w_{2}^{-}-a^{0}\right| \leq \xi,\left|w_{2}^{+} / w_{2}^{+}-a^{0}\right| \leq \xi ; \\
& \left|w_{3}^{-} / w_{2}^{-}-a^{1}\right| \leq \xi,\left|w_{3}^{+} / w_{2}^{+}-a^{2}\right| \leq \xi ; \\
& \left|w_{4}^{-} / w_{2}^{-}-a^{5}\right| \leq \xi,\left|w_{4}^{+} / w_{2}^{+}-a^{5}\right| \leq \xi ; \\
& \left|w_{5}^{-} / w_{2}^{-}-a^{4}\right| \leq \xi,\left|w_{5}^{+} / w_{2}^{+}-a^{5}\right| \leq \xi ; \\
& \left|w_{6}^{-} / w_{2}^{-}-a^{6}\right| \leq \xi,\left|w_{6}^{+} / w_{2}^{+}-a^{6}\right| \leq \xi ; \\
& \left|w_{7}^{-} / w_{2}^{-}-a^{7}\right| \leq \xi,\left|w_{7}^{+} / w_{2}^{+}-a^{8}\right| \leq \xi ; \\
& \sum_{7}^{7} w_{l}^{+}+w_{j}^{-} \geq 1, \quad \sum_{l=1, l \neq j}^{7} w_{l}^{-}+w_{j}^{+} \leq 1 ; \\
& \quad \sum_{l=1, l \neq j} \quad w_{j}^{+} \geq w_{j}^{-} \geq 0 ; j=1,2,3,4,5,6,7 .
\end{array}
$$

Solving Model 3 by LINGO software package, we can obtain $\xi^{*}=0.396$ and the weight vector of criteria $w_{j}^{D_{4}{ }^{*}}=([0.079,0.085],[0.039,0.040],[0.057,0.057],[0.147,0.173]$, $[0.105,0.141],[0.204,0.223],[0.282,0.368])^{\mathrm{T}}$.

Since $U^{+}\left(e n v\left(h_{S}^{B W}\right)\right)=a^{8}$, we can calculate the maximal deviation $C I=5.284$. By Eq. (5), we have $C R=0.075$, which is acceptable. Considering that the expertise of group mem- 
bers is different, the consistency requirements of different experts are also different. In this case study, $\mathrm{D}_{2}$ as a general manager, who may be less professional in evaluating the criteria compared with other experts. Thus, the CR threshold of $\mathrm{D}_{2}$ is relaxed to 0.2 . The minimum absolute differences and the consistency ratios for the other three experts are listed in Table 3.

Step 4. After obtaining the acceptable weight of each criterion evaluated by all experts, we use Eq. (6) to integrate the weights of all experts for each criterion. Then, by Eqs (7) and (8), the mean value $\bar{w}_{j}$ of the integrated interval weight and the normalized weight $w_{j}$ for each criterion is obtained. The results are shown in Table 3.

Table 3. The weight of each criterion

\begin{tabular}{|c|c|c|c|c|c|c|c|}
\hline & $\mathrm{D}_{1}$ & $\mathrm{D}_{2}$ & $\mathrm{D}_{3}$ & $\mathrm{D}_{4}$ & $w_{j}^{*}$ & $\bar{w}_{j}$ & $w_{j}$ \\
\hline$c_{1}$ & {$[0.112,0.126]$} & {$[0.149,0.157]$} & {$[0.256,0.384]$} & {$[0.079,0.085]$} & {$[0.122,0.143]$} & 0.133 & 0.144 \\
\hline$c_{2}$ & {$[0.088,0.096]$} & {$[0.062,0.083]$} & {$[0.053,0.069]$} & {$[0.039,0.040]$} & {$[0.060,0.068]$} & 0.064 & 0.070 \\
\hline$c_{3}$ & {$[0.034,0.037]$} & {$[0.112,0.112]$} & {$[0.127,0.181]$} & {$[0.057,0.057]$} & {$[0.058,0.065]$} & 0.062 & 0.067 \\
\hline$c_{4}$ & {$[0.192,0.250]$} & {$[0.354,0.386]$} & {$[0.119,0.148]$} & {$[0.147,0.173]$} & {$[0.171,0.211]$} & 0.191 & 0.207 \\
\hline$c_{5}$ & {$[0.053,0.053]$} & {$[0.061,0.061]$} & {$[0.036,0.042]$} & {$[0.105,0.141]$} & {$[0.061,0.069]$} & 0.065 & 0.070 \\
\hline$c_{6}$ & {$[0.141,0.161]$} & {$[0.042,0.046]$} & {$[0.059,0.080]$} & {$[0.204,0.223]$} & {$[0.117,0.136]$} & 0.127 & 0.137 \\
\hline$c_{7}$ & {$[0.295,0.338]$} & {$[0.189,0.212]$} & {$[0.200,0.225]$} & {$[0.282,0.368]$} & {$[0.258,0.305]$} & 0.282 & 0.305 \\
\hline$\xi$ & 0.409 & 0.557 & 0.396 & 0.396 & & & \\
\hline $\mathrm{CR}$ & 0.080 & 0.105 & 0.075 & 0.075 & & & \\
\hline
\end{tabular}

Step 5. The experts are required to evaluate each alternative with respect to each criterion based on the linguistic term set (Shi \& Ye, 2017): $\left\{s_{0}\right.$ : extremely low, $s_{1}$ : very low, $s_{2}:$ low, $s_{3}$ : slightly low, $s_{4}$ : medium, $s_{5}$ : lightly high, $s_{6}:$ high, $s_{7}:$ very high, $s_{8}$ : extremely high\} . For conserve space, we just take $\mathrm{D}_{4}$ as an example, the HFL decision matrix formed by the expert's evaluations is shown in Table 4. We suppose that the expert is risk-neutral, which implies $\varsigma=0.5$. Then, the transformed HFL decision matrix of expert $\mathrm{D}_{4}$ (shown in Table 5) can be obtained by the supplementary regulation given in Section 3.1. As we can see, $c_{1}, c_{2}, c_{3}, c_{4}, c_{5}, c_{6}$ are benefit criteria while $c_{7}$ is a cost criterion. According to Eqs (9) and (10), the optimal supplier $A_{0}$ is found out whose values on all criteria are optimal.

Table 4 . The HFL decision matrix provided by $D_{4}$

\begin{tabular}{|c|c|c|c|c|c|c|c|}
\hline & $c_{1}$ & $c_{2}$ & $c_{3}$ & $c_{4}$ & $c_{5}$ & $c_{6}$ & $c_{7}$ \\
\hline $\mathrm{A}_{1}$ & $\left\{s_{4}, s_{5}\right\}$ & $\left\{s_{2}, s_{3}, s_{4}\right\}$ & $\left\{s_{3}, s_{4}\right\}$ & $\left\{s_{5}, s_{6}\right\}$ & $\left\{s_{4}, s_{5}, s_{6}\right\}$ & $\left\{s_{5}, s_{6}\right\}$ & $\left\{s_{4}, s_{5}\right\}$ \\
\hline $\mathrm{A}_{2}$ & $\left\{s_{7}\right\}$ & $\left\{s_{3}, s_{4}\right\}$ & $\left\{s_{4}, s_{5}, s_{6}\right\}$ & $\left\{s_{7}, s_{8}\right\}$ & $\left\{s_{5}, s_{6}\right\}$ & $\left\{s_{6}\right\}$ & $\left\{s_{1}, s_{2}, s_{3}\right\}$ \\
\hline $\mathrm{A}_{3}$ & $\left\{s_{3}, s_{4}\right\}$ & $\left\{s_{4}, s_{5}, s_{6}\right\}$ & $\left\{s_{1}, s_{2}\right\}$ & $\left\{s_{4}, s_{5}\right\}$ & $\left\{s_{3}\right\}$ & $\left\{s_{3}, s_{4}\right\}$ & $\left\{s_{5}, s_{6}\right\}$ \\
\hline $\mathrm{A}_{4}$ & $\left\{s_{5}, s_{6}, s_{7}\right\}$ & $\left\{s_{4}, s_{5}\right\}$ & $\left\{s_{5}\right\}$ & $\left\{s_{6}\right\}$ & $\left\{s_{3}, s_{4}\right\}$ & $\left\{s_{6}, s_{7}\right\}$ & $\left\{s_{3}, s_{4}\right\}$ \\
\hline
\end{tabular}


Table 5. The transformed HFL decision matrix with respect to $D_{4}$

\begin{tabular}{|c|c|c|c|c|c|c|c|}
\hline & $c_{1}$ & $c_{2}$ & $c_{3}$ & $c_{4}$ & $c_{5}$ & $c_{6}$ & $c_{7}$ \\
\hline $\mathrm{A}_{0}$ & $\left\{s_{7}, s_{7}, s_{7}\right\}$ & $\left\{s_{4}, s_{5}, s_{6}\right\}$ & $\left\{s_{5}, s_{5}, s_{5}\right\}$ & $\left\{s_{7}, s_{7.5}, s_{8}\right\}$ & $\left\{s_{5}, s_{5.5}, s_{6}\right\}$ & $\left\{s_{6}, s_{6.5}, s_{7}\right\}$ & $\left\{s_{1}, s_{2}, s_{3}\right\}$ \\
\hline $\mathrm{A}_{1}$ & $\left\{s_{4}, s_{4.5}, s_{5}\right\}$ & $\left\{s_{2}, s_{3}, s_{4}\right\}$ & $\left\{s_{3}, s_{3.5}, s_{4}\right\}$ & $\left\{s_{5}, s_{5.5}, s_{6}\right\}$ & $\left\{s_{4}, s_{5}, s_{6}\right\}$ & $\left\{s_{5}, s_{5.5}, s_{6}\right\}$ & $\left\{s_{4}, s_{4.5}, s_{5}\right\}$ \\
\hline $\mathrm{A}_{2}$ & $\left\{s_{7}, s_{7}, s_{7}\right\}$ & $\left\{s_{3}, s_{3.5}, s_{4}\right\}$ & $\left\{s_{4}, s_{5}, s_{6}\right\}$ & $\left\{s_{7}, s_{7.5}, s_{8}\right\}$ & $\left\{s_{5}, s_{5.5}, s_{6}\right\}$ & $\left\{s_{6}, s_{6}, s_{6}\right\}$ & $\left\{s_{1}, s_{2}, s_{3}\right\}$ \\
\hline $\mathrm{A}_{3}$ & $\left\{s_{3}, s_{3.5}, s_{4}\right\}$ & $\left\{s_{4}, s_{5}, s_{6}\right\}$ & $\left\{s_{1}, s_{1.5}, s_{2}\right\}$ & $\left\{s_{4}, s_{4.5}, s_{5}\right\}$ & $\left\{s_{3}, s_{3}, s_{3}\right\}$ & $\left\{s_{3}, s_{3.5}, s_{4}\right\}$ & $\left\{s_{5}, s_{5.5}, s_{6}\right\}$ \\
\hline $\mathrm{A}_{4}$ & $\left\{s_{5}, s_{6}, s_{7}\right\}$ & $\left\{s_{4}, s_{4.5}, s_{5}\right\}$ & $\left\{s_{5}, s_{5}, s_{5}\right\}$ & $\left\{s_{6}, s_{6}, s_{6}\right\}$ & $\left\{s_{3}, s_{3.5}, s_{4}\right\}$ & $\left\{s_{6}, s_{6.5}, s_{7}\right\}$ & $\left\{s_{3}, s_{3.5}, s_{4}\right\}$ \\
\hline
\end{tabular}

Afterword, normalize the decision matrix for each expert by Eqs (11) and (12), and the normalized HFL decision matrix for each expert is obtained as follows:

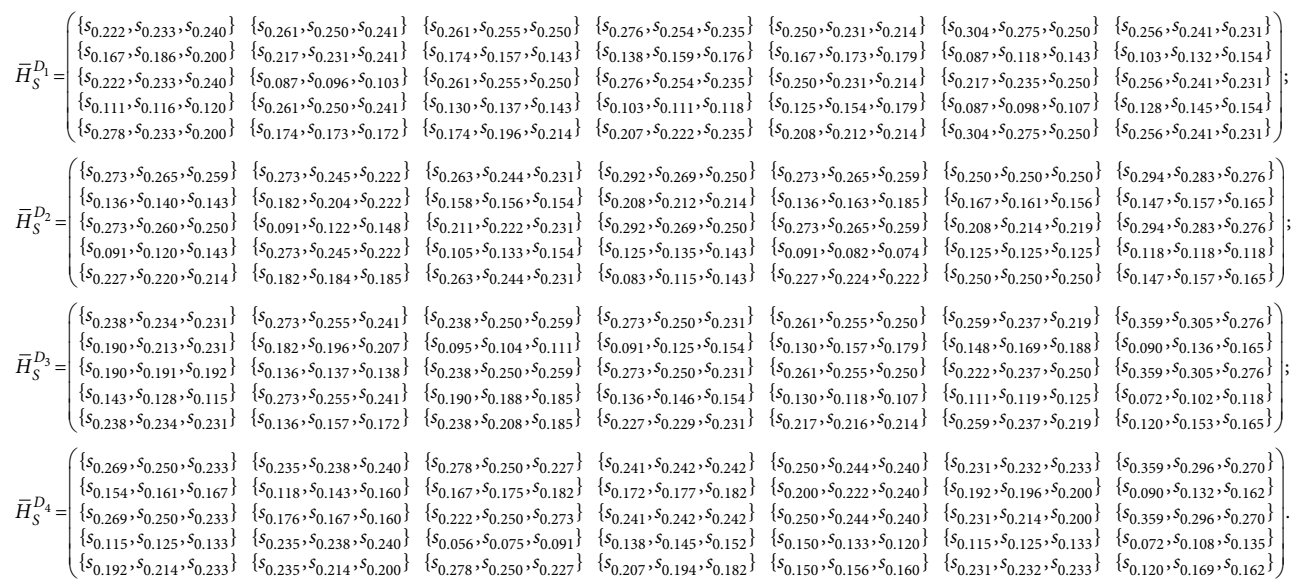

For example, $\bar{h}_{S}^{D_{4}}\left(x_{11}\right)=\left\{s_{4 /(7+4+7+3+5)}, s_{4.5 /(7+4+7+3+6)}, s_{5 /(7+5+7+4+7)}\right\}=\left\{s_{0.154}, s_{0.161}, s_{0.167}\right\}$.

By Eq. (13) we can aggregate all normalized HFL decision matrices into a collective normalized HFL decision matrix as (here we set $\lambda=0.4$ ):

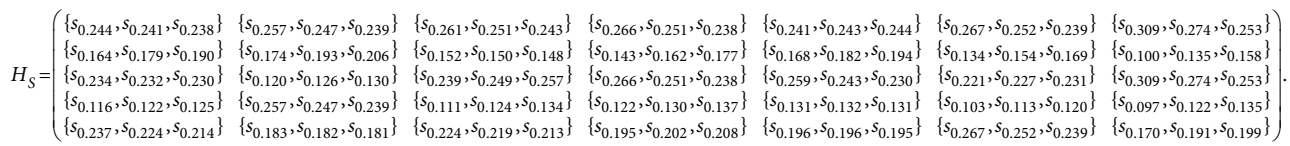

Following the example above:

$$
\begin{aligned}
h_{S}\left(x_{11}\right)= & \text { GHFLWA }{ }_{\lambda}\left(\bar{h}_{S}^{D_{1}}\left(x_{11}\right), \bar{h}_{S}^{D_{2}}\left(x_{11}\right), \bar{h}_{S}^{D_{3}}\left(x_{11}\right), \bar{h}_{S}^{D_{4}}\left(x_{11}\right)\right)= \\
& \left\{s_{\left(0.4 \times 0.167^{0.4}+0.1 \times 0.136^{0.4}+0.2 \times 0.190^{0.4}+0.3 \times 0.154^{0.4}\right)^{1 / 0.4}}\right. \\
& s_{\left(0.4 \times 0.186^{0.4}+0.1 \times 0.140^{0.4}+0.2 \times 0.213^{0.4}+0.3 \times 0.161^{0.4}\right)^{1 / 0.4},} \\
& s_{\left.\left(0.4 \times 0.200^{0.4}+0.1 \times 0.143^{0.4}+0.2 \times 0.231^{0.4}+0.3 \times 0.167^{0.4}\right)^{1 / 0.4}\right\}=} \\
& \left\{s_{0.164}, s_{0.179}, s_{0.190}\right\} .
\end{aligned}
$$

Then, based on the weights of criteria derived in Step 4, we can obtain the normalized weighted HFL decision matrix by Eq. (14), shown as:

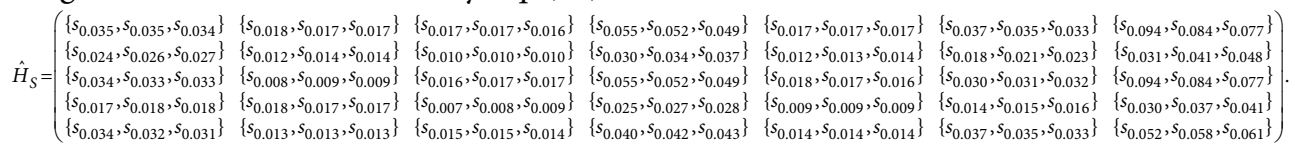


Following the example above:

$\hat{h}_{S}\left(x_{11}\right)=w_{1} h_{S}\left(x_{11}\right)=\left\{s_{0.144 \times 0.164}, s_{0.144 \times 0.179}, s_{0.144 \times 0.190}\right\}=\left\{s_{0.024}, s_{0.026}, s_{0.027}\right\}$.

Step 6. Calculate the overall performance values $\tilde{P}_{i}$ by Eq. (15). The mean value $P_{i}$ can be obtained. Next, use Eq. (16) to compute the suppliers' utility degree $Q_{i}$. Finally, we can rank the alternatives in descending order by Eq. (17). The calculation results are displayed in Table 6. From this table, we can find that the alternative $A_{2}$ with the largest utility degree should be chosen as the most suitable supplier.

Table 6. The ranking result of each alternative

\begin{tabular}{|c|c|c|c|c|}
\hline supplier & $\tilde{P}_{i}$ & $P_{i}$ & $Q_{i}$ & Rank \\
\hline $\mathrm{A}_{0}$ & $\left\{s_{0.273}, s_{0.257}, s_{0.243}\right\}$ & 0.258 & 1 & \\
\hline $\mathrm{A}_{1}$ & $\left\{s_{0.137}, s_{0.159}, s_{0.173}\right\}$ & 0.156 & 0.605 & 3 \\
\hline $\mathrm{A}_{2}$ & $\left\{s_{0.255}, s_{0.243}, s_{0.233}\right\}$ & 0.244 & 0.946 & 1 \\
\hline $\mathrm{A}_{3}$ & $\left\{s_{0.120}, s_{0.131}, s_{0.138}\right\}$ & 0.130 & 0.504 & 4 \\
\hline $\mathrm{A}_{4}$ & $\left\{s_{0.205}, s_{0.209}, s_{0.209}\right\}$ & 0.208 & 0.806 & 2 \\
\hline
\end{tabular}

\section{Discussions}

In this section, a sensitivity analysis is given to show the effect of different parameter values in the proposed method on the final ranking of alternatives. Furthermore, a comparative analysis is provided to demonstrate the usability and validity of the proposed HFL-BWMARAS method.

\subsection{Sensitivity analysis}

In the above calculation process, when transforming the HFL decision matrices with respect to the experts by the supplementary regulation of HFLEs, the parameter $\varsigma$ is taken as 0.5 based on the assumption that all experts are supposed to be intermediate-risk preferred. However, if the experts provide the value of $\varsigma$ based on the low risk preferences or the high risk preferences, i.e., $\varsigma=0$ or $\varsigma=1$, it is obvious that the utility degree $Q_{i}$ of each alternative will be changed. The different utility degrees of alternatives with respect to different values of $\varsigma$ can be obtained as shown in Table 7 .

Table 7. The utility degrees of alternatives with respect to different value of $\varsigma$

\begin{tabular}{|c|c|c|c|}
\hline $\mathrm{Q}_{\mathrm{i}}$ & $\varsigma=0$ & $\varsigma=0.5$ & $\varsigma=1$ \\
\hline$Q_{1}$ & 0.609 & 0.605 & 0.605 \\
\hline$Q_{2}$ & 0.946 & 0.946 & 0.942 \\
\hline$Q_{3}$ & 0.496 & 0.504 & 0.512 \\
\hline$Q_{4}$ & 0.806 & 0.806 & 0.795 \\
\hline
\end{tabular}




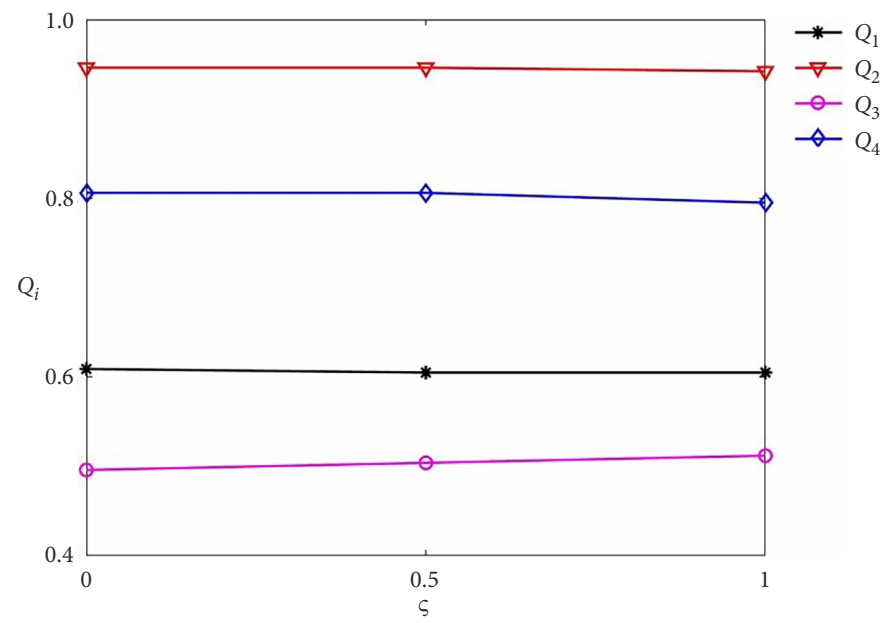

Figure 1 . The sensitivity analysis results with respect to different values of $\varsigma$

The sensitivity analysis results can be displayed in Figure 1. As we can see, although the change of the value of parameter $\varsigma$ has an effect on the value of the alternative utility degree $Q_{i}$, there is no effect on the ranking result of each alternative. This indicates that the supplementary regulation used in the proposed HFL-BWM-ARAS method is less affected by the risk preference of experts, and thus the ranking results obtained by the method have high reliability to some extent.

\subsection{Comparative analysis}

The TOPSIS and VIKOR methods are two commonly used MCDM methods for ranking alternatives. At present, these two methods have been extended in the HFL environment (Beg, \& Rashid, 2013; Liao et al., 2015a; Ghadikolaei, Madhoushi, \& Divsalar, 2018). To show the effectiveness and advantage of the proposed HFL-BWM-ARAS method, this paper compares the HFL-TOPSIS and HFL-VIKOR methods with the proposed method.

Based on the criteria weights obtained by the HFL-BWM, the ranking results of the DSCF suppliers can be derived by these three methods, respectively. As displayed in Table 8, we can see that the ranking results obtained by the HFL-TOPSIS method are the same as those obtained by the HFL-BWM-ARAS method, that is, $A_{2}$ is the best alternative and $A_{3}$ is the worst one. This, to some extent, shows the effectiveness of the proposed method. The results obtained by the HFL-VIKOR method, as displayed in Table 9, are slightly different from those obtained by the HFL-BWM-ARAS method. The worst alternative $\mathrm{A}_{3}$ is the same as the other two methods, but the best alternative is the compromise solution between $\mathrm{A}_{4}$ and $A_{1}$. Although both the HFL-TOPSIS and HFL-VIKOR methods are based on the distance between performance value of the alternatives and that of the positive or negative ideal solution, the HFL-VIKOR method is based on more complex distance measurement than the HFL-TOPSIS method in calculating the compromise measure for each alternative, and its purpose is to provide a maximum utility for the majority and a minimum regret for the op- 
ponent (Ghadikolaei et al., 2018). Therefore, the results obtained by the HFL-VIKOR method are a little different from those obtained by the HFL-TOPSIS and HFL-ARAS methods. The ranking results can be compared intuitively by Figure 2 .

In addition, the differences between the proposed method and the HFL-TOPSIS and HFL-VIKOR methods are clear. Firstly, the HFL-ARAS method considers the weights of both experts and criteria, while the HFL-TOPSIS and HFL-VIKOR methods only consider the weights of criteria. This shows that the HFL-ARAS method is more applicable and scientific

Table 8. The ranking results derived from the HFL-TOPSIS method

\begin{tabular}{|c|c|c|c|c|}
\hline Supplier & $D_{i}^{-}$ & $D_{i}^{+}$ & $R C_{i}$ & Rank \\
\hline $\mathrm{A}_{1}$ & 25 & 39 & 0.391 & 3 \\
\hline $\mathrm{A}_{2}$ & 46 & 18 & 0.717 & 1 \\
\hline $\mathrm{A}_{3}$ & 16 & 47 & 0.254 & 4 \\
\hline $\mathrm{A}_{4}$ & 39 & 25 & 0.609 & 2 \\
\hline
\end{tabular}

Note: $D_{i}^{-}$refers to the HFL positive-ideal solution, $D_{i}^{+}$refers to the HFL negative-ideal solution, and $R C_{i}$ refers to the HFL relative closeness to the ideal solution.

Table 9. The ranking results derived from the HFL-VIKOR method

\begin{tabular}{|c|c|c|c|c|}
\hline Supplier & $S_{i}$ & $R_{i}$ & $Q_{i}$ & Rank \\
\hline $\mathrm{A}_{1}$ & 0.519 & 0.135 & 0.294 & 2 \\
\hline $\mathrm{A}_{2}$ & 0.410 & 0.305 & 0.552 & 3 \\
\hline $\mathrm{A}_{3}$ & 0.611 & 0.193 & 0.669 & 4 \\
\hline $\mathrm{A}_{4}$ & 0.387 & 0.181 & 0.133 & 1 \\
\hline
\end{tabular}

Note: $S_{i}$ represents the HFL distance-based group utility, $R_{i}$ represents the HFL individual regret measure, and $Q_{i}$ represents the HFL compromise measure.

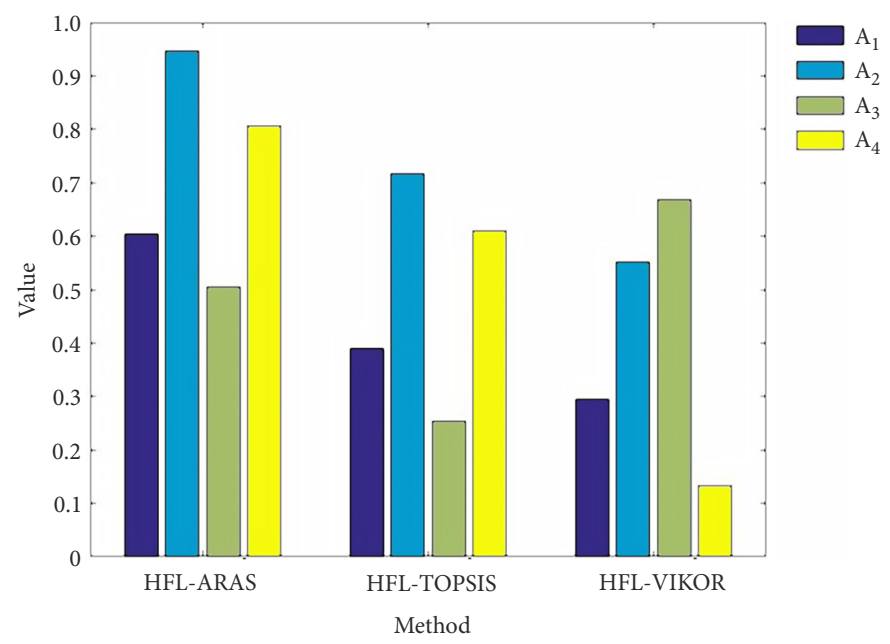

Figure 2. Comparison of the HFL-ARAS, HFL-TOPSIS and HFL-VIKOR methods 
in solving practical problems. Secondly, the HFL-ARAS method only finds the positive ideal solution, while the HFL-TOPSIS and HFL-VIKOR methods need to find the positive-ideal solution and the negative-ideal solution, respectively. This indicates that, for the MCDM problems with more criteria or alternatives, the HFL-ARAS method can improve the operational efficiency to some extent and has better operability. Finally, for the HFL-TOPSIS and HFL-VIKOR methods, it is necessary to calculate the distances between each evaluation of alternatives on each criterion and that of the ideal solution, which is time-consuming and reduces the accuracy of the results. By contrast, the calculation process of the HFL-ARAS method is simpler, and thus the accuracy and reliability of the results is higher.

Through the case study, we can see that the proposed method has the following advantages:

(1) On the premise of ensuring the accuracy of information expression, HFLTS expresses the expert's linguistic evaluation information more directly;

(2) The proposed method can obtain a reasonable and efficacious solution for complex decision-making problems by taking advantage of the ability of expressing preferences with high consistency linear evaluation provided by the BWM and the advantage of the ability of efficient ranking of the ARAS method;

(3) The change of parameters in the normalization process has little effect on the final results, which proves the reliability of the method to some extent;

(4) The ranking tool of the proposed method, HFL-ARAS approach, is simple to operate, with strong adaptability and wide applicability and has some advantages over other methods in HFL environment.

\section{Conclusions}

Financing difficulty is one of the important factors for the development of most SMEs, especially in the real manufacturing industry. With the gradual digitization of SCF, SMEs have opportunities to further solve this problem and it is very important for them to select suitable DSCF suppliers to provide good financing services for their development. This paper studied a new multi-expert MCDM method for SMEs to select the most suitable DSCF supplier in the process of solving financing problems. Comparing with conventional fuzzy sets, the HFLTS can better express the preferences of experts since it is closer to human cognition and perceptions. The BWM can reduce the number of comparisons among criteria and has higher consistency, and the ARAS method can be readily applied into many fields to solve practical problems. Motivated by these concerns, this paper combined the BWM and ARAS methods and extended them to the HFL environment. The HFL-BWM was used to derive the weights of criteria while the HFL-ARAS was developed to determine the optimal supplier. The concrete operation steps of the multi-expert MCDM model were given. A case study was then displayed.

In the proposed method, the extension of ARAS method in HFL environment is calculated according to the subscripts of linguistic terms. However, this calculation method for subscripts has been proved to be defective to some extent (Liao et al., 2019b). Therefore, in the future, we shall research that converting HFLTSs to numerical values by score functions 
and integrating other MCDM methods with the ARAS method under the HFL environment. Considering the advantages of the proposed integrated method, it can also be applied to solve cognitive complex decision-making problems in other fields, such as the talent selection problem, location selection problem and risk evaluation problem. It would be interesting to expand their applications to more areas to prove their effectiveness and practicability.

\section{Funding}

The work was supported by the National Natural Science Foundation of China under Grant 71571156, 71971145 and the 2019 Sichuan Planning Project of Social Science under Grant SC18A007.

\section{Author contributions}

Huchang Liao and Zhi Wen conceived the study and were responsible for the design and development of the data analysis. Huchang Liao, Zhi Wen and Lili Liu were responsible for data collection and analysis. Lili Liu were responsible for data interpretation. Huchang Liao and Zhi Wen wrote the first draft of the article.

\section{Disclosure statement}

The authors have no competing financial, professional, or personal interests from other parties that are related to this paper.

\section{References}

Abdullah, L., \& Najib, L. (2016). A new preference scale MCDM method based on interval-valued intuitionistic fuzzy sets and the analytic hierarchy process. Soft Computing, 20(12) 511-523. https://doi.org/10.1007/s00500-014-1519-y

Armin, C., Mohammad, M. P., \& Mostafa, H. (2018). Applying a hybrid BWM-VIKOR approach to supplier selection: a case study in the Iranian agricultural implements industry. International Journal of Applied Decision Sciences, 11(3), 274-301. https://doi.org/10.1504/IJADS.2018.092796

Badi, I. A., Abdulshahed, A. M., \& Shetwan, A. G. (2018). A case study of supplier selection for a steelmaking company in Libya by using the combinative distance-based assessment (CODAS) model. Decision Making: Applications in Management and Engineering, 1(1), 1-12. https://doi.org/10.31181/dmame180101b

Badi, I., \& Ballem, M. (2018). Supplier selection using rough BWM-MAIRCA model: a case study in pharmaceutical supplying in Libya. Decision Making: Applications in Management and Engineering, 1(2), 16-33. https://doi.org/10.31181/dmame1802016b

Baležentis, T., \& Streimikiene, D. (2017). Multi-criteria ranking of energy generation scenarios with Monte Carlo simulation. Applied Energy, 185, 862-871.

https://doi.org/10.1016/j.apenergy.2016.10.085

Beg, I., \& Rashid, T. (2013). TOPSIS for hesitant fuzzy linguistic term sets. International Journal of Intelligent Systems, 28, 1162-1171. https://doi.org/10.1002/int.21623 
Büyüközkan, G., \& Göcer, F. (2018). An extension of ARAS methodology under interval valued intuitionistic fuzzy environment for digital supply chain. Applied Soft Computing, 69, 634-654.

https://doi.org/10.1016/j.asoc.2018.04.040

Dahooie, J. H., Zavadskas, E. K., Abolhasani, M., Vanaki, A., \& Turskis, Z. (2018). A novel approach for evaluation of projects using an interval-valued fuzzy additive ratio assessment (ARAS) method: a case study of oil and gas well drilling projects. Symmetry, 10(2), 45.

https://doi.org/10.3390/sym10020045

Ecer, F. (2018). An integrated fuzzy AHP and ARAS model to evaluate mobile banking services. Technological and Economic Development of Economy, 24(2), 1-26.

https://doi.org/10.3846/20294913.2016.1255275

Ghadikolaei, A. S., Madhoushi, M., \& Divsalar, M. (2018). Extension of the VIKOR method for group decision making with extended hesitant fuzzy linguistic information. Neural Computing and Applications, 30(12), 3589-3602. https://doi.org/10.1007/s00521-017-2944-5

Guo, S., \& Zhao, H. (2017). Fuzzy best-worst multi-criteria decision-making method and its applications. Knowledge-Based Systems, 121, 23-31. https://doi.org/10.1016/j.knosys.2017.01.010

Hafezalkotob, A., Hafezalkotob, A., Liao, H. C., \& Herrera, F. (2019a). An overview of MULTIMOORA for multi-criteria decision-making: Theory, developments, applications, and challenges. Information Fusion, 51, 145-177. https://doi.org/10.1016/j.inffus.2018.12.002

Hafezalkotob, A., Hafezalkotob, A., Liao, H. C., \& Herrera, F (2019b). Interval MULTIMOORA method: Integrating interval Borda rule and interval best-west-method-based weighting model. IEEE Transactions on Cybernetics, 99, 1-13. https://doi.org/10.1109/TCYB.2018.2889730

Karabasevic, D., Zavadskas, E. K., Turskis, Z., \& Stanujkic, D. (2016). The framework for the selection of personnel based on the SWARA and ARAS methods under uncertainties. Informatica, 27, 49-65. https://doi.org/10.15388/Informatica.2016.76

Keršulienè, V., Zavadskas, E. K., \& Turskis, Z. (2010). Selection of rational dispute resolution method by applying new step-wise weight assessment ratio analysis (SWARA). Journal of Business Economics and Management, 11(2), 243-258. https://doi.org/10.3846/jbem.2010.12

Keshavarz Ghorabaee, M. K., Amiri, M., Zavadskas, E. K., Hooshmand, R., \& Antuchevičienè, J. (2017). Fuzzy extension of the CODAS method for multi-criteria market segment evaluation. Journal of Business Economics and Management, 18(1), 1-19. https://doi.org/10.3846/16111699.2016.1278559

Liao, C. N., Fu, Y. K., \& Wu, L. C. (2016). Integrated FAHP, ARAS-F and MSGP methods for green supplier evaluation and selection. Technological and Economic Development of Economy, 22, 651669. https://doi.org/10.3846/20294913.2015.1072750

Liao, H. C., Mi, X. M., Yu, Q., \& Luo, L. (2019a). Hospital performance evaluation by a hesitant fuzzy linguistic best worst method with inconsistency repairing. Journal of Cleaner Production, 232, 657671. https://doi.org/10.1016/j.jclepro.2019.05.308

Liao, H. C., Qin, R., Gao, C. Y., Wu, X.L., Hafezalkotob, A., \& Herrera, F. (2019b). Score-HeDLiSF: A score function of hesitant fuzzy linguistic term set based on hesitant degrees and linguistic scale functions: An application to unbalanced hesitant fuzzy linguistic MULTIMOORA, Information Fusion, 48, 39-54. https://doi.org/10.1016/j.inffus.2018.08.006

Liao, H. C., Xu, Z. S., Herrera-Viedma, E., \& Herrera, F. (2018). Hesitant fuzzy linguistic term set and its application in decision making: a state-of-the-art survey. International Journal of Fuzzy Systems, 20(7), 2084-2110. https://doi.org/10.1007/s40815-017-0432-9

Liao, H. C., Xu, Z. S., \& Zeng, X. J. (2015a). Hesitant fuzzy linguistic VIKOR method and its application in qualitative multiple criteria decision making. IEEE Transactions on Fuzzy Systems, 23(5), 1343-1355. https://doi.org/10.1109/TFUZZ.2014.2360556

Liao, H. C., Xu, Z. S., Zeng, X. J., \& Merigó, J. M. (2015b). Qualitative decision making with correlation coefficients of hesitant fuzzy linguistic term sets. Knowledge-Based Systems, 76, 127-138.

https://doi.org/10.1016/j.knosys.2014.12.009 
Mardani, A., Jusoh, A., Halicka, K., Ejdys, J., Magruk, A., \& Ahmad, U. N. U. (2018). Determining the utility in management by using multi-criteria decision support tools: a review. Economic ResearchEkonomska Istraživanja, 31, 1666-1716. https://doi.org/10.1080/1331677X.2018.1488600

Mi, X. M., Tang, M., Liao, H. C., Shen, W. J., \& Lev, B. (2019a). The state-of-the-art survey on integrations and applications of the best worst method in decision making: Why, what, what for and what's next? Omega, 87, 205-225. https://doi.org/10.1016/j.omega.2019.01.009

Mi, X. M., Wu, X. L., Tang, M., Liao, H. C., Al-Barakati, A., Altalhi, A. H., \& Herrera, F. (2019b). Hesitant fuzzy linguistic analytic hierarchical process with prioritization, consistency checking and inconsistency repairing. IEEE Access, 7(1), 44135-44149. https://doi.org/10.1109/ACCESS.2019.2908701

Mou, Q., Xu, Z. S., \& Liao, H. C. (2016). An intuitionistic fuzzy multiplicative best-worst method for multi-criteria group decision making. Information Sciences, 374, 224-239. https://doi.org/10.1016/j.ins.2016.08.074

Radović, D., Stević, Ž., Pamučar, D., Zavadskas, E. K., Badi, I., Antucheviciene, J., \& Turskis, Z. (2018). Measuring performance in transportation companies in developing countries: a novel rough ARAS model. Symmetry, 10, 1-24. https://doi.org/10.3390/sym10100434

Rezaei, J. (2015). Best-worst multi-criteria decision-making method. Omega, 53, 49-57. https://doi.org/10.1016/j.omega.2014.11.009

Rodríguez, R. M., Martinez, L., \& Herrera, F. (2012). Hesitant fuzzy linguistic term sets for decision making. IEEE Transactions on Fuzzy Systems, 20(1), 109-119. https://doi.org/10.1109/TFUZZ.2011.2170076

Shi, L. L., \& Ye, J. (2017). Cosine measures of linguistic neutrosophic numbers and their application in multiple attribute group decision-making. Information, 8(4), 117. https://doi.org/10.3390/info8040117

Sremac, S., Stević, Ž., Pamučar, D., Arsić, M., \& Matić, B. (2018). Evaluation of a third-party logistics (3PL) provider using a rough SWARA-WASPAS model based on a new rough dombi aggregator. Symmetry, 10(8), 305. https://doi.org/10.3390/sym10080305

Stanujkic, D., Zavadskas, E. K., Karabasevic, D., Turskis, Z., \& Keršulienė, V. (2017). New group decision-making ARCAS approach based on the integration of the SWARA and the ARAS methods adapted for negotiations. Journal of Business Economics \& Management, 18, 599-618. https://doi.org/10.3846/16111699.2017.1327455

Stević, Ž., Pamučar, D., Zavadskas, E. K., Ćirović, G., \& Prentkovskis, O. (2017). The selection of wagons for the internal transport of a logistics company: A novel approach based on rough BWM and rough SAW methods. Symmetry, 9(11), 264. https://doi.org/10.3390/sym9110264

Sugihara, K., Ishii, H., \& Tanaka, H. (2004). Interval priorities in AHP by interval regression analysis. European Journal of Operational Research, 158(3), 745-754. https://doi.org/10.1016/S0377-2217(03)00418-1

Sun, R. X., Hu, J. H., Zhou, J. D., \& Chen, X. H. (2018). A hesitant fuzzy linguistic projection-based MABAC method for patients' prioritization. International Journal of Fuzzy Systems, 20(7), 21442160. https://doi.org/10.1007/s40815-017-0345-7

Tosun, Ö., \& Akyüz, G. (2015). A fuzzy TODIM approach for the supplier selection problem. International Journal of Computational Intelligence Systems, 8(2), 317-329. https://doi.org/10.1080/18756891.2015.1001954

Turskis, Z., \& Zavadskas, E. K. (2010a). A new fuzzy additive ratio assessment method (ARAS-F). Case study: the analysis of fuzzy multiple criteria in order to select the logistic centers location. Transport, 25, 423-432. https://doi.org/10.3846/transport.2010.52

Turskis, Z., \& Zavadskas, E. K. (2010b). A novel method for multiple criteria analysis: grey additive ratio assessment (ARAS-G) method. Informatica, 21, 597-610. https://iospress.metapress.com/index/N7J8531184645761 
Tuysuz, F., \& Berna, Ş. (2017). A hesitant fuzzy linguistic term sets-based AHP approach for analyzing the performance evaluation factors: an application to cargo sector. Complex \& Intelligent Systems, 2, 1-9. https://doi.org/10.1007/s40747-017-0044-x

$\mathrm{Xu}, \mathrm{Z}$. S. (2013). Priority weight intervals derived from intuitionistic multiplicative preference relations. IEEE Transactions on Fuzzy Systems, 21, 642-654. https://doi.org/10.1109/TFUZZ.2012.2226893

Yu, C. X., Shao, Y. F., Wang, K., \& Zhang, L. P. (2019). A group decision making sustainable supplier selection approach using extended TOPSIS under interval-valued Pythagorean fuzzy environment. Expert Systems with Applications, 121, 1-17. https://doi.org/10.1016/j.eswa.2018.12.010

Zarbakhshnia, N., Soleimani, H., \& Ghaderi, H. (2018). Sustainable third-party reverse logistics provider evaluation and selection using fuzzy SWARA and developed fuzzy COPRAS in the presence of risk criteria. Applied Soft Computing, 65, 307-319. https://doi.org/10.1016/j.asoc.2018.01.023

Zavadskas, E. K., \& Turskis, Z. (2010). A new additive ratio assessment (ARAS) method in multicriteria decision-making. Technological and Economic Development of Economy, 16, 159-172. https://doi.org/10.3846/tede.2010.10

Zavadskas, E. K., Turskis, Z., \& Vilutiene, T. (2010). Multiple criteria analysis of foundation instalment alternatives by applying additive ratio assessment (ARAS) method. Archives of Civil \& Mechanical Engineering, 10, 123-141. https://doi.org/10.1016/S1644-9665(12)60141-1

Zhang, L., Hu, H. P., \& Zhang, D. (2015). A credit risk assessment model based on SVM for small and medium enterprises in supply chain finance. Financial Innovation, 1(1), 14. https://doi.org/10.1186/s40854-015-0014-5

Zhang, Z., \& Wu, C. (2014). Hesitant fuzzy linguistic aggregation operators and their applications to multiple attribute group decision making. Journal of Intelligent \& Fuzzy Systems, 26, 2185-2202. https://doi.org/10.3233/IFS-130893

Zhao, D., Wang, D., \& Wang, B. (2018). Research on operational risk evaluation of online supply chain finance based on fuzzy AHP. Basic \& Clinical Pharmacology \& Toxicology, 122, 49-49.

Zheng, Y. H., Xu, Z. S, He, Y., \& Liao, H. C. (2018). Severity assessment of chronic obstructive pulmonary disease based on hesitant fuzzy linguistic COPRAS method. Applied Soft Computing, 69, 60-71. https://doi.org/10.1016/j.asoc.2018.04.035

Zhu, B., \& Xu, Z. S. (2014). Consistency measures for hesitant fuzzy linguistic preference relations. IEEE Transactions on Fuzzy Systems, 22, 35-45. https://doi.org/10.1109/TFUZZ.2013.2245136 